\title{
Diagnóstico micológico: de los métodos convencionales a los moleculares
}

\author{
Mycological diagnosis: From conventional \\ methods to molecular ones \\ Verónica J. Tangarife-Castaño MSc', \\ Sindy V. Flórez-Muñoz Biol', Ana C. Mesa-Arango PhD
}

\begin{abstract}
Resumen: La incidencia de las infecciones fúngicas ha aumentado en las últimas décadas como consecuencia del incremento en el número de pacientes con factores predisponentes. Tanto el diagnóstico como el tratamiento de estas infecciones continúan siendo un reto para el personal de la salud. Aunque las especies de los géneros Candida, Aspergillus y Cryptococcus continúan siendo las más frecuentes, es notoria la emergencia de especies que no se habían reconocido anteriormente como patógenas para el hombre. Ante este panorama, el diagnóstico adecuado y oportuno de estas infecciones es de gran relevancia para la instauración de un tratamiento eficaz y, de esta manera, para impactar en la morbilidad y mortalidad que suelen causar algunas micosis, principalmente en los individuos inmunocomprometidos. Con esta revisión se pretende mostrar de manera general aspectos clínicos, epidemiológicos y, principalmente, relacionados con el diagnóstico de las infecciones fúngicas más frecuentes, partiendo de los métodos convencionales hasta las técnicas moleculares que actualmente se tratan de implementar en busca de un la prueba estándar de referencia que pueda superar la sensibilidad, la especificidad, la rapidez y el costo-efectividad de los métodos que se han utilizado hasta ahora en el diagnostico micológico.
\end{abstract}

Palabras clave: micosis, técnicas de laboratorio clínico, técnicas de diagnóstico molecular, epidemiología.

Abstract: Fungal infections incidence has risen in recent decades due to the increase of many predisposing factors. The diagnosis and treatment of such infections continue to be a challenge for clinicians. Although some species of the genus Candida, Aspergillus and Cryptococcus remain as the

'Microbióloga y Bioanalista. Candidata a MSc en Ciencias Básicas Biomédicas, Universidad de Antioquia. Estudiante de maestría, Grupo de Investigación Dermatológica (GRID), Universidad de Antioquia. Coordinadora Científica, Editora Médica Colombiana S.A. Medellín, Colombia.

Estudiante de Biología, Universidad de Antioquia. Grupo de Investigación Dermatológica (GRID), Universidad de Antioquia. Medellín, Colombia.

3Bacterióloga y laboratorista clínica, especialista en Micología Médica, MSc en Biología Experimental, PhD en Microbiología y Parasitología. Docente, Facultad de Medicina, Universidad de Antioquia. Grupo de Investigación Dermatológica (GRID), Universidad de Antioquia. Medellín, Colombia. Correspondencia: Carrera 5 ID No. 62-29. Oficina 303, Edificio Manuel Uribe Ángel (MUA), Facultad de Medicina, Universidad de Antioquia. Correo electrónico: ana.mesa@udea.edu.co.

Conflicto de intereses: las autoras declaran que no tienen conflicto de intereses

Medicina \& Laboratorio 2015; $21: 211-242$

Módulo I (La clínica y el laboratorio), número I I 0. Editora Médica Colombiana S.A. $2015^{\odot}$

Recibido el 17 de mayo de 2015; aceptado el 30 de junio de 2015

Medicina \& Laboratorio Volumen 21, Números 5-6, 2015. 
most frequent, have emerged more fungal species not formerly recognized as pathogenic. Therefore, there is an increasing need for an appropriate and quick diagnosis of such infections in order to start an effective treatment and thus to impact on morbidity in the majority of patients and on mortality in the immunosuppressed. This review focuses in clinical and epidemiological features, but also in the diagnostic of most common fungal infections, based on conventional methods and new molecular techniques to search an standard test that be to more sensitive and specific, faster and cost-effective.

Key words: Mycoses, clinical laboratory techniques, molecular diagnostic techniques, epidemiology.

Tangarife-Castaño VJ, Flórez-Muñoz SV, Mesa-Arango AC. Diagnóstico micológico: de los métodos convencionales a los moleculares. Medicina \& Laboratorio 2015; 21 : 211 -242.

L a incidencia de las infecciones fúngicas ha aumentado significativamente en las últimas décadas y actualmente representan un importante problema de salud para los humanos. Este incremento se ha producido principalmente por el creciente número de pacientes sometidos a tratamientos con inmunosupresores para trasplantes, que reciben quimio o radioterapia, neutropénicos, enfermos que han sufrido cirugía grave (principalmente abdominal) o inmunocomprometidos, especialmente por la infección causada por el virus de la inmunodeficiencia humana $(\mathrm{VIH})$. Existen otros factores que contribuyen a la aparición de nuevos casos de infecciones fúngicas y hacen a los pacientes más vulnerables, como el uso de antibióticos de amplio espectro, la hospitalización prolongada, la nutrición parenteral, la edad avanzada y la diabetes [1-4].

La presentación de las infecciones fúngicas puede variar desde formas superficiales (piel y mucosas) a invasivas o diseminadas, estas últimas asociadas a altas tasas de morbilidad y mortalidad, a pesar de la disponibilidad de antifúngicos con diferente espectro de actividad para su tratamiento [5]. La epidemiología de las infecciones fúngicas ha cambiado de manera importante en los últimos años y, aunque las especies de los géneros Candida, Aspergillus y Cryptococcus continúan siendo las más frecuentes, es notoria la aparición de nuevas especies, algunas de ellas con baja sensibilidad o resistentes a los principales antifúngicos de uso clínico [2,6]. En esta revisión presentamos de manera general diferentes aspectos de las infecciones fúngicas más frecuentes, con énfasis en los métodos diagnósticos más utilizados, así como la tendencia actual en este tópico.

\section{Importancia de los hongos en la salud humana}

Los hongos son microorganismos de distribución mundial con una diversidad que puede oscilar entre 600.000 y 700.000 especies en la naturaleza [7,8], de las cuales aproximadamente 200, y con tendencia a aumentar, pueden producir enfermedades en el hombre [9-I I]. Las infecciones causadas por hongos comprenden desde micosis superficiales, las cuales son comunes y relativamente fáciles de curar, hasta sistémicas e invasivas, que pueden amenazar la vida de las personas [12] debido, principalmente, a las condiciones de las poblaciones que afectan y a las dificultades para realizar el diagnóstico. Lo anterior, puede impedir la instauración de una terapia oportuna y eficaz. Además, el incremento de la resistencia antimicótica de diferentes especies, así como la emergencia de otras menos sensibles o resistentes, es una situación que ha ido complicando el panorama de las micosis [13]. 
Aunque existen diversos estudios sobre la frecuencia, la incidencia y la prevalencia de las infecciones fúngicas en algunos países, la mayoría de estos están localizados geográficamente, lo que impide que la dimensión mundial del impacto sobre la salud humana se conozca completamente. Además, estas infecciones no son reconocidas por la Organización Mundial de la Salud u otros organismos de salud pública en el mundo como un motivo de estudio y manejo prioritario, por lo que actualmente no se cuenta con programas de vigilancia y notificación de enfermedades micóticas instaurados, a excepción de la coccidioidomicosis, la cual debe ser notificada a los Centros para el Control y Prevención de Enfermedades (CDC) de los Estados Unidos [12].

La incidencia de las micosis es mayor en las zonas tropicales y subtropicales, donde probablemente la temperatura y la humedad faciliten el crecimiento y la transmisión de los agentes causales [14]. Estas infecciones afectan personas de cualquier condición social, etaria y género; no obstante, las alteraciones en el sistema inmune, la edad avanzada, los tratamientos con corticosteroides, la quimioterapia para el cáncer, la diabetes y la infección con el VIH/SIDA representan las principales condiciones de riesgo para padecerlas [12].

Las micosis superficiales son tal vez las más estudiadas y de las que más datos se disponen a nivel mundial. En América Latina, por ejemplo, en países como Brasil, Chile y Venezuela se registran aproximadamente entre 500 y 1.500 casos de micosis superficiales anualmente [15-17]. Por su parte, las infecciones fúngicas invasivas y diseminadas tienen una incidencia mucho más baja que las superficiales; sin embargo, presentan tasas de mortalidad más elevadas, llegando a superar el 50\% de los casos, a pesar de la disponibilidad de diversos agentes antimicóticos en el mercado. Se estima que anualmente pueden morir cerca de un millón y medio de personas por infecciones fúngicas invasivas, superando las cifras de mortalidad por tuberculosis o malaria [12].

La frecuencia de las infecciones fúngicas invasivas por hongos filamentosos ha aumentado durante la última década, debido, en parte, al incremento en el número de pacientes con factores de riesgo. Dentro de estas infecciones, la aspergilosis y la fusariosis son las más frecuentes e importantes por las altas tasas de morbilidad y mortalidad que causan en pacientes neutropénicos o trasplantados (de órganos sólidos o de progenitores hematopoyéticos) [18,19]. Nucci y colaboradores (2010) [20], en una revisión sistemática sobre la epidemiología de las infecciones invasivas en América Latina reportadas de 1990 a 2008, registraron entre 86 y 924 casos de candidemia en Brasil, I 16 en México, entre 25 y 265 en Argentina, entre 50 y 130 en Chile y I 10 en Costa Rica., Por otro lado, una evaluación de la incidencia de la criptococosis, llevada a cabo por el Grupo de Estudio Iberoamericano de criptococosis (2003) [2I], registró un total de 266 aislamientos clínicos de Cryptococcus neoformans en Argentina, Brasil, Chile, Colombia, México, Perú, Venezuela, Guatemala y España.

En Colombia no existen estudios poblacionales sobre la incidencia o la prevalencia de las diferentes micosis, en parte por no tratarse de enfermedades de notificación obligatoria. Sin embargo, se han publicado diferentes estudios institucionales que dan idea de la situación de las diferentes micosis desde el punto de vista clínico, epidemiológico y de diagnóstico. Con respecto a las infecciones superficiales, en un centro hospitalario de la ciudad de Medellín, se demostró que son la sexta causa de consulta dermatológica [22]. Entre éstas infecciones, las dermatofitomicosis y la onicomicosis se han registrado como las más prevalentes [23,24]. 
En cuanto a las micosis subcutáneas, la esporotricosis es la más importante en Colombia [25]. Un estudio retrospectivo de I I años llevado a cabo en un centro dermatológico de referencia nacional registró 60 casos de esporotricosis en personas provenientes de diferentes regiones del país [25]. Asimismo, otros autores, en un estudio retrospectivo de II años encontraron I 42 (27\%) casos de esporotricos, confirmados por aislamiento del agente etiológico, en 5 I2 pacientes remitidos por sospecha de la enfermedad [26].

Otras infecciones importantes en Colombia y otros países de América Latina son las conocidas micosis endémicas como la histoplasmosis y la paracoccidioidomicosis [27-29]. De acuerdo a una encuesta realizada en diferentes departamentos del país, durante 16 años, se notificaron 434 casos de histoplasmosis, de los cuales los pacientes infectados con el VIH fueron los más afectados [30]. Además, esta población también padece con frecuencia otra micosis importante en nuestro país, la criptococosis [3।].

La epidemiología de las infecciones fúngicas invasivas y diseminadas es aún más desconocida en Colombia. Estudios aislados en diferentes instituciones muestran la importancia de algunas de estas micosis, como es el caso de la candidemia con cifras considerables en la incidencia y la prevalencia (2,3 casos/ / .000 pacientes y I,4\%, respectivamente) [32]. Un estudio más reciente registró una mortalidad del 39,5\% por candidemia en pacientes críticos no neutropénicos [33]. A pesar del impacto en la salud humana de la aspergilosis y de la fusariosis, en Colombia se carecen de estudios epidemiológicos sobre estas infecciones.

Dado el incremento de las diferentes micosis, así como la morbilidad y mortalidad asociada, la prevención, el diagnóstico y el tratamiento oportuno de este tipo de infecciones es una conducta ineludible; $y$, aunque se han desarrollado nuevos métodos de diagnóstico y diferentes fármacos antifúngicos, continúan siendo un reto para el clínico.

\section{Las principales infecciones fúngicas y su etiología}

Los hongos de los géneros Candida, Aspergillus y Cryptococcus continúan siendo los principales agentes etiológico de las micosis invasivas y diseminadas. Sin embargo, especies de otros géneros han ido ganado importancia dentro de la micología médica debido a la incidencia y mortalidad que causan o a la baja sensibilidad o resistencia que presentan a uno o varios antifúngicos. En la tabla I se indican los principales agentes causales de las micosis más importantes, así como las formas infecciosas del hongo, el mecanismo de infección, los principal(es) órgano(s) blanco, las estructuras que ayudan al diagnóstico y el tiempo que puede tardar la observación del hongo en el cultivo.

\section{Micosis superficiales}

Las micosis superficiales, es decir, aquellas que afectan la piel y anexos (pelo y las uñas), y las mucosas, son las más frecuentes y son causadas principalmente por los hongos del género Malassezia y del grupo de los dermatofitos (tiñas). Dentro de éstas, las infecciones de las uñas (onicomicosis) son las más comunes y, aunque se presentan en cualquier región del mundo, afectando aproximadamente el 25\% de la población, la mayoría de los casos se registran en regiones tropicales [12]. 


\begin{tabular}{|c|c|c|c|c|c|c|}
\hline Hongo & $\begin{array}{l}\text { Fuente de la } \\
\text { infección }\end{array}$ & $\begin{array}{l}\text { Principal forma } \\
\text { infecciosa }\end{array}$ & $\begin{array}{l}\text { Modo de } \\
\text { adquirir la } \\
\text { infección }\end{array}$ & $\begin{array}{l}\text { Sitio de infección } \\
\text { más común }\end{array}$ & $\begin{array}{l}\text { Principal } \\
\text { estructura que } \\
\text { se observa en el } \\
\text { examen directo } \\
\text { a partir de las } \\
\text { muestras clínica }\end{array}$ & $\begin{array}{l}\text { Tiempo } \\
\text { aproximado } \\
\text { de incubación } \\
\text { del cultivo } \\
\text { (días) }\end{array}$ \\
\hline $\begin{array}{l}\text { Aspergillus } \\
\text { spp. }\end{array}$ & Ambiente & Conidias & Inhalación & $\begin{array}{l}\text { Pulmones, ojos, } \\
\text { uñas, oído }\end{array}$ & Hifas dicótomas & $1-6$ \\
\hline Candida spp. & $\begin{array}{l}\text { Microbiota } \\
\text { endógena }\end{array}$ & Blastoconidias & $\begin{array}{l}\text { Invasión } \\
\text { directa/ } \\
\text { Disemina- } \\
\text { ción }\end{array}$ & $\begin{array}{l}\text { Mucosas intes- } \\
\text { tinal, vaginal y } \\
\text { oral, uñas, sangre }\end{array}$ & $\begin{array}{l}\text { Blastoconidias, } \\
\text { pseudohifas e } \\
\text { hifas }\end{array}$ & $1-2$ \\
\hline $\begin{array}{l}\text { Cryptococcus } \\
\text { neoformans }\end{array}$ & $\begin{array}{l}\text { Suelos con- } \\
\text { taminados } \\
\text { con heces } \\
\text { de aves } \\
\text { (palomas) }\end{array}$ & $\begin{array}{l}\text { Levaduras } \\
\text { sin cápsula y } \\
\text { basidiosporas }\end{array}$ & Inhalación & $\begin{array}{l}\text { Meninges, pul- } \\
\text { món y piel (por } \\
\text { diseminación) }\end{array}$ & $\begin{array}{l}\text { Blastoconidias } \\
\text { encapsuladas }\end{array}$ & 3 \\
\hline $\begin{array}{l}\text { Histoplasma } \\
\text { capsulatum }\end{array}$ & $\begin{array}{l}\text { Suelos con- } \\
\text { taminados } \\
\text { con heces } \\
\text { de murcié- } \\
\text { lagos } \\
\text { y de aves }\end{array}$ & Microconidias & Inhalación & $\begin{array}{l}\text { Pulmón, médula } \\
\text { ósea sangre, piel } \\
\text { o mucosas (por } \\
\text { diseminación) }\end{array}$ & Blastoconidias & $10-30$ \\
\hline $\begin{array}{l}\text { Paracocaidioides } \\
\text { brasiliensis }\end{array}$ & Suelo & $\begin{array}{l}\text { Conidias y } \\
\text { fragmentos de } \\
\text { hifas }\end{array}$ & $\begin{array}{l}\text { Inhalación/ } \\
\text { trauma }\end{array}$ & $\begin{array}{l}\text { Pulmón, piel o } \\
\text { mucosas (por } \\
\text { diseminación }\end{array}$ & $\begin{array}{l}\text { Blastoconidias } \\
\text { multigemantes }\end{array}$ & $10-45$ \\
\hline $\begin{array}{l}\text { Complejo } \\
\text { Sporothrix } \\
\text { schenkii }\end{array}$ & $\begin{array}{l}\text { Suelo y } \\
\text { plantas }\end{array}$ & $\begin{array}{l}\text { Conidias y } \\
\text { fragmentos de } \\
\text { hifas }\end{array}$ & Trauma & $\begin{array}{l}\text { Piel o tejido ce- } \\
\text { lular subcutáneo, } \\
\text { articulaciones, } \\
\text { pulmones y } \\
\text { meninges }\end{array}$ & $\begin{array}{l}\text { En algunos } \\
\text { casos blastoco- } \\
\text { nidias }\end{array}$ & $3-12$ \\
\hline Dermatofitos & $\begin{array}{l}\text { Hombres } \\
\text { y animales } \\
\text { infectados, } \\
\text { suelo }\end{array}$ & $\begin{array}{l}\text { Conidias } \\
\text { (artroconidias) } \\
\text { e hifas }\end{array}$ & $\begin{array}{l}\text { Contacto } \\
\text { directo o } \\
\text { con fómites } \\
\text { infectados }\end{array}$ & $\begin{array}{l}\text { Piel, cabello y } \\
\text { uñas }\end{array}$ & Hifas & $3-14$ \\
\hline $\begin{array}{l}\text { Malassezia } \\
\text { spp. }\end{array}$ & $\begin{array}{l}\text { Microbiota } \\
\text { endógena }\end{array}$ & $\begin{array}{l}\text { Blastoconidias } \\
\text { e hifas }\end{array}$ & $\begin{array}{l}\text { Directa a } \\
\text { partir de la } \\
\text { microbiota }\end{array}$ & $\begin{array}{l}\text { Piel, cuero cabe- } \\
\text { lludo, oído }\end{array}$ & $\begin{array}{l}\text { Blastoconidias } \\
\text { e hifas }\end{array}$ & $3-7$ \\
\hline Fusarium spp. & $\begin{array}{l}\text { Suelo y } \\
\text { plantas }\end{array}$ & $\begin{array}{l}\text { Conidias y } \\
\text { fragmentos de } \\
\text { hifas }\end{array}$ & $\begin{array}{l}\text { Inhalación/ } \\
\text { trauma, di- } \\
\text { seminación } \\
\text { a partir de } \\
\text { infección en } \\
\text { piel o uñas }\end{array}$ & $\begin{array}{l}\text { Pulmón, ojos, } \\
\text { uñas y sangre }\end{array}$ & $\begin{array}{l}\text { Hifas (en } \\
\text { algunos casos } \\
\text { pueden ser } \\
\text { dicótomas) }\end{array}$ & $2-6$ \\
\hline Mucorales & $\begin{array}{l}\text { Suelo y } \\
\text { plantas }\end{array}$ & $\begin{array}{l}\text { Esporangios- } \\
\text { poras }\end{array}$ & $\begin{array}{l}\text { Inhalación } \\
\text { o contami- } \\
\text { nación de } \\
\text { heridas o } \\
\text { quemaduras }\end{array}$ & $\begin{array}{l}\text { Pulmón, piel, } \\
\text { senos paranasa- } \\
\text { les, ojos, oídos, } \\
\text { sangre y piel } \\
\text { (en pacientes } \\
\text { quemados) }\end{array}$ & Hifas aseptadas & $\mid-5$ \\
\hline
\end{tabular}

Los agentes causales de micosis superficiales más importantes son los dermatofitos Trichophyton rubrum y Trichophyton interdigitale (antes conocido como Trichophyton mentagrophytes), las levaduras del género Candida y algunos hongos filamentosos no dermatofitos, involucrados principalmente en casos de onicomicosis, como Fusarium spp., Neoscytalidium (antes denominado Scytalidium) dimidiatum, Aspergillus spp., Penicilium spp., Scopulariopsis spp. y Acremonium spp. 
[35]. Estos últimos han mostrado un incremento importante y suelen ser resistentes a los tratamientos antifúngicos sistémicos, por lo que frecuentemente se asocian con falla terapéutica [36].

\section{Micosis subcutáneas}

Las micosis subcutáneas comprometen principalmente la piel y el tejido celular subcutáneo. En situaciones de inmunosupresión se pueden presentar casos de diseminación. La mayor incidencia se presenta en regiones tropicales. La espotrotricosis (causada por especies del complejo Sporothrix schenckii), la cromoblastomicosis (causada por diversos agentes dematiáceos como Fonsecaea pedrosoi, Phialophora verrucosa y Cladophialophora carrionii), los eumicetomas (causada por una variedad de hongos filamentosos, siendo Madurella mycetomatis, Madurella grisea, Pseudallescheria boydii y Leptosphaeria senegalensis los responsables de aproximadamente el $90 \%$ de los casos) y la lobomicosis (causada por Lacazia loboi), son las micosis subcutáneas más importantes [37-40].

\section{Infecciones por levaduras}

Las principales levaduras patógenas pertenecen a los géneros Candida y Cryptococcus. Dentro del género Candida se ha descrito un número importante de especies patógenas, a pesar de que forman parte de la microbiota de las mucosas y se pueden encontrar transitoriamente en la piel. En contraste, las especies de Cryptococcus spp., son levaduras ambientales y la infección se adquiere por inhalación. Además, en los últimos años, aunque en menor proporción, han aumentado los casos de infecciones por otras levaduras.

\section{Candidiasis}

El espectro de la candidiasis es amplio y abarca desde infecciones superficiales (orofaríngeas, vaginales y de la piel) hasta formas más severas como la candidiasis sistémica [2,3,4I]. La candidiasis orofaríngea afecta el paladar duro y blando, la faringe, la lengua y la mucosa oral. Generalmente es uno de los primeros signos clínicos de la infección causada por el VIH [42]. La candidiasis vulvovaginal supone una de las enfermedades fúngicas más frecuentes y se estima que alrededor del 75\% de las mujeres presentan al menos un episodio durante su vida. El incremento en la incidencia de este tipo de candidiasis se ha asociado al uso de antibióticos de amplio espectro y al aumento de pacientes inmunocomprometidos [43].

La mayoría de las infecciones diseminadas e invasivas (70\% al 90\%) están causadas por levaduras del género Candida [4I]. La candidemia tiene una mortalidad asociada de alrededor del $40 \%$ al 50\% dependiendo de la población afectada y de la especie implicada [3,4I ,44]. Globalmente, el Complejo Candida albicans (Candida albicans, Candida dubliniensis y Candida africana) es el de mayor importancia clínica, ya que es el que se aísla con mayor frecuencia en los casos de candidiasis (45\% al 50\%) [45]. Generalmente, las infecciones superficiales causadas por esta levadura no son letales; sin embargo, en pacientes inmunocomprometidos la diseminación se asocia a una alta mortalidad [6]. Los factores de riesgo más importantes para la candidiasis diseminada por Candida albicans son las alteraciones en la mucosa gastrointestinal, la presencia de catéteres venosos y el uso de antibióticos de amplio espectro [46].

En los últimos años, las especies de Candida no-albicans han aumentado su incidencia significativamente y suponen aproximadamente el 50\% de todos los episodios de candidemia [44,47]. 
Entre estas especies se encuentran principalmente las del Complejo Candida glabrata (Candida nivariensis y Candida bracarensis) y aquellas del Complejo Candida parapsilosis (Candida parapsilosis, Candida orthopsilosis y Candida metapsilosis) y, en menor proporción, Candida tropicalis y Candida krusei. Aunque la mayoría de estas levaduras suelen ser menos virulentas que el Complejo Candida albicans, algunas son más resistentes a uno o varios antifúngicos o presentan tendencia a desarrollarla rápidamente $[4,48]$.

\section{Criptococosis}

Las especies del género Cryptococcus son los agentes etiológicos de la criptococosis, una infección de distribución mundial que se adquiere por la inhalación de basidiosporas del ambiente. Las especies más frecuentes son Cryptococcus neoformans y Cryptococcus gattii, las cuales se diferencian en la epidemiología y los cuadros clínicos que producen. El hábitat natural de Cryptococcus neoformans es el suelo o la materia orgánica contaminada con guano de aves, mientras que el de Cryptococcus gattii se encuentra asociado con árboles de eucalipto [49]. A diferencia de Cryptococcus neoformans, que afecta especialmente individuos inmunocomprometidos, la infección por Cryptococcus gattii es más frecuente en individuos inmunocompetentes [50].

\section{Otras levaduras y hongos levaduriformes}

Levaduras menos frecuentes como Rhodotorula spp., Pichia spp. y Saccharomyces cerevisiae, así como hongos denominados levaduriformes (en inglés, yeast-like) como Geotrichum capitatum y Trichosporon spp., también tienen impacto en la salud humana. En concreto, las especies de Trichosporon forman parte de la microbiota de diferentes zonas del cuerpo humano y, aunque el porcentaje de casos de infección invasiva que producen no es muy elevado, son la segunda o tercer causa de fungemia, después de la producida por Candida spp. Los individuos más susceptibles a infecciones por Trichosporon spp., son los pacientes leucémicos, en los que se registra una tasa de mortalidad que oscila entre el $60 \%$ y el $80 \%$. El tratamiento de estas infecciones representa un reto terapéutico debido a su reducida sensibilidad a los principales antifúngicos de uso clínico $[|3,5|]$.

\section{Infecciones por hongos filamentosos}

Actualmente los hongos filamentosos de los géneros Aspergillus, Fusarium, Scedosporium, Penicillium y algunos del orden Mucorales (Rhizopus oryzae, Mucor circinelloides, Rhizomucor pusillus y Lichteimia (antes Absidia) corymbifera, son una causa importante de infecciones en el humano, principalmente del tipo invasivas, que si bien son menos frecuentes respecto a las producidas por levaduras, la mortalidad asociada suele ser mayor [52-54].

\section{Aspergilosis}

Las aspergilosis corresponde a la infección causada por las especies del género Aspergillus, que comprende desde cuadros alérgicos, como la aspergilosis broncopulmonar alérgica (ABPA) o los aspergilomas (crecimiento del hongo dentro de una cavidad preexistente), hasta formas más graves, como la infección pulmonar o la aspergilosis invasiva [55]. Aspergillus fumigatus causa aproximadamente el $90 \%$ de los casos y es el agente causal más importante de enfermedad fúngica invasora por hongos filamentosos en pacientes neutropénicos y trasplantados (de 
órganos sólidos o de progenitores hematopoyéticos). Otras especies como Aspergillus terreus, Aspergillus flavus, Aspergillus nidulans, Aspergillus niger y Aspergillus lentulus muestran una incidencia creciente en pacientes con factores predisponentes [55-59].

\section{Otros hongos filamentosos}

Las infecciones causadas por Fusarium spp. y Scedosporium spp. son menos frecuentes que las causadas por Aspergillus spp., pero suelen llegar a ser más graves por el tipo de pacientes que afectan y la baja sensibilidad o multirresistencia a los antifúngicos disponibles, lo que se correlaciona con la falta de respuesta clínica al tratamiento. Algunas especies del género Fusarium causan infecciones leves como la onicomicosis que pueden afectar cualquier individuo o severas y diseminadas que se presentan en pacientes con trastornos hematológicos, que reciben terapia citotóxica o trasplantados en tratamiento con corticosteroides [60]. Las especies de Fusarium suelen ser resistentes o poco sensibles a varios antimicóticos [61,62]. Algunas especies del orden Mucorales representan otro grupo de agentes de importancia clínica por la alta mortalidad que causan en pacientes con factores predisponentes como cáncer hematológico, neutropenia y monocitopenia, en tratamientos con altas dosis de corticosteroides, con hiperglicemias no controladas, diabetes, entre otros [63].

\section{Micosis endémicas}

Las micosis endémicas, aquellas que ocurren generalmente en regiones localizadas geográficamente, son producidas por los hongos dimórficos Histoplasma capsulatum, Paracoccidioides brasiliensis, Blastomyces dermatitidis y Coccidioides immitis/posadassi [64-66], siendo los dos primeros de importancia en Colombia.

Finalmente, es importante referirnos a Pneumocystis jirovecii, un hongo con características particulares que lo diferencian de los antes descritos. Éste es un microorganismo oportunista con capacidad de causar neumonía en pacientes inmunocomprometidos, principalmente con el síndrome de inmunodeficiencia adquirida (SIDA) [67].

\section{Diagnóstico clínico de las infecciones fúngicas}

El diagnóstico adecuado de las infecciones fúngicas inicia por la sospecha clínica. Los síntomas y los signos de estas infecciones son variados y dependen del agente etiológico, la localización de la misma y el estado inmune del hospedero. En escasas ocasiones la historia personal y los hallazgos del examen físico son suficientes para establecer el diagnóstico de una infección fúngica [10,68]; no obstante, las infecciones fúngicas suelen confundirse con las producidas por bacterias, por lo que establecer el contexto en que se producen es lo que permite sospecharlas [68].

Una serie de datos clínicos, epidemiológicos y terapéuticos como el motivo de consulta, los antecedentes médicos y quirúrgicos, el uso de medicamentos, la procedencia y la historia de viajes a zonas endémicas de algunas enfermedades micóticas, pueden orientar al médico sobre una posible infección fúngica y a establecer un adecuado diagnóstico. Otros factores como la tenencia de mascotas o exposición a otros animales, la ocupación (p. ej. agricultura, caza, arqueología, espeleología, jardinería, construcciones, entre otros), a pesar de ser considerados menos importantes, son de ayuda, especialmente en los casos de micosis endémicas [68]. 
La presencia de enfermedades subyacentes como la diabetes mellitus descompensada, las neoplasias hematológicas, la fibrosis pulmonar, la enfermedad granulomatosa crónica y la infección por el $\mathrm{VIH}$, al igual que la historia reciente de trasplante alogénico o tratamiento para la enfermedad injerto contra huésped y el tratamiento con agentes inmunosupresores como los corticosteroides, los agentes quimioterapéuticos para la terapia contra el cáncer y los antibióticos de amplio espectro, constituyen algunos de los principales factores de riesgo de la infección por hongos $[12,63,69]$.

Durante el examen físico es importante realizar la exploración de la piel, los ojos, la nariz, la boca y la garganta, entre otras, en búsqueda de las lesiones referidas por el paciente o aquellas que puedan no haber sido notadas por éste previamente. De igual manera, se debe determinar si existen signos de presión intracraneal o neumonitis, y realizar la evaluación cardíaca y abdominal. Estos hallazgos si bien no son específicos pueden dar indicios de que se trata de una infección fúngica. No obstante, en la mayoría de los casos se requiere de exámenes de laboratorio que ayuden a establecer el diagnóstico [68].

\section{Diagnóstico por el laboratorio de las infecciones fúngicas}

La identificación precisa de los agentes causales es de fundamental importancia en el diagnóstico de una infección micótica desde el punto de vista ecológico, epidemiológico y terapéutico, dado que las rutas de infección, las diferencias en los regímenes terapéuticos y la susceptibilidad pueden variar entre las diferentes especies. Es por ello que disponer de pruebas diagnósticas específicas, sensibles, rápidas y confiables es una permanente preocupación en el campo de la micología médica $[70,7 \mathrm{I}]$.

El diagnóstico por imaginología, la observación de las estructuras micóticas (blastoconidias, hifas y pseudohifas) en muestras biológicas de los pacientes infectados y el cultivo de éstas en busca del aislamiento del agente causal y de su identificación, continúan siendo el estándar de referencia en el diagnóstico micológico a pesar de su limitada sensibilidad y especificidad, y de los avances en el desarrollo de técnicas rápidas con las que se pretende identificar el agente etiológico directamente de muestras clínicas [72].

El diagnóstico micológico por métodos convencionales no es fácil ya que depende del hospedero, la calidad de la muestra, el microorganismo y la experiencia de quien hace el diagnóstico. Muchos de los pacientes que padecen infecciones fúngicas se encuentran en serias condiciones de salud por lo que la obtención de las muestras, principalmente mediante procedimientos invasivos, puede estar contraindicada. De ahí que actualmente exista una tendencia al desarrollo y aplicación de métodos no invasivos y cultivo-independientes, entre los que se incluyen la detección de antígenos, anticuerpos y ADN fúngico por técnicas de biología molecular [72,73].

\section{Tipo de muestras}

El éxito en el aislamiento de los agentes etiológicos de las micosis puede depender de la recolección, el transporte, el procesamiento rápido y correcto de las muestras y de la inoculación en el medio de cultivo y a la temperatura de incubación adecuados. Las muestras para el diagnóstico micológi- 
co deben estar correctamente identificadas y ser tomadas en condiciones asépticas, previo a la instauración de cualquier tratamiento antimicrobiano y luego de la suspensión de antifúngicos tópicos o sistémicos mínimo una semana previa a la toma de la muestra, evitando la contaminación ambiental o con la microbiota. Además, es indispensable que la recolección y el almacenaje de las muestras se haga en los recipientes estériles correspondientes según el tipo de muestra [74].

El tipo de muestra para el diagnóstico micológico se elige acuerdo a la sintomatología, el tipo de lesión y la sospecha clínica [ I I]. Para las lesiones en el cuero cabelludo se recomienda raspar escamas de piel y tomar trozos de pelo con raíz del sitio de la lesión utilizando pinzas estériles [75]. A partir de las lesiones con sospecha de onicomicosis se toman escamas de la parte más profunda de las zonas decoloradas o distróficas, y tanto de la superficie como de la base, la región subungueal y los bordes laterales de la uña [75].

En el caso de las lesiones en piel, se toman escamas del borde activo de la lesión, costras, vesículas o pústulas, utilizando un bisturí. De la misma manera se procede ante la sospecha de una micosis profunda con manifestaciones en piel o mucosas (úlceras, descarga sinusal, nódulos verrugosos o costrosos). En algunos casos es necesario acudir a la obtención de la muestra por biopsia. La citología, los hisopados o las biopsias son útiles para el diagnóstico de infecciones en la cavidad oral o mucosa vaginal. Por otro lado, las muestras de sangre, esputo, lavado broncoalveolar, líquido cefalorraquídeo, exudados de tejidos y orina son fundamentales, principalmente en el diagnóstico de las infecciones fúngicas invasivas, pulmonares y meningitis [76].

Los espécimen deben ser transportados y procesados, preferiblemente dentro de las dos horas después de la recolección. Los fragmentos de pelo y las escamas de piel pueden ser recogidos, almacenados y transportados en una hoja de papel doblada a temperatura ambiente. Los hisopados de mucosa se recogen en medios de transporte adecuados (p. ej. medio de Stuart o solución fisiológica estéril) cuando se sospecha una infección por Candida spp. Los demás especímenes pueden ser transportados en medios como caldo de infusión de cerebro y corazón (BHI; del inglés Brain Heart Infusion). El uso de contenedores estériles a prueba de vertidos es recomendado para el transporte de las muestras $[74,76]$.

Cuando se supone un retraso en el transporte o procesamiento de la muestra o la posible contaminación bacteriana se puede adicionar penicilina $(20 \mathrm{U} / \mathrm{mL})$, estreptomicina ( $1.000 .000 \mu \mathrm{g} /$ $\mathrm{mL})$ o cloranfenicol $(0,2 \mathrm{mg} / \mathrm{mL})$ y almacenar bajo refrigeración a $4{ }^{\circ} \mathrm{C}$ máximo por 24 horas; a excepción de la sangre, la cual se debe mantener a temperatura ambiente o incubar a $35^{\circ} \mathrm{C}$. En el caso del líquido cefalorraquídeo el transporte debe ser a temperatura ambiente para que la viabilidad de microorganismos como Cryptococcus neoformans e Histoplasma capsulatum no se vea afectada $[74,76]$.

\section{Métodos convencionales para el diagnóstico de infecciones fúngicas}

\section{Evaluación microscópica directa de muestras biológicas}

El examen directo de muestras biológicas es un procedimiento diagnóstico valioso que permite la observación de estructuras micóticas que sugieren una infección [76]. Las preparaciones para 
el examen directo en fresco se realizan en un portaobjetos mediante la mezcla de una pequeña cantidad de muestra con solución salina, principalmente para muestra vaginales, o hidróxido de potasio $(\mathrm{KOH})$ al $10 \%$, el cual aclara la muestra permitiendo una mejorar visualización de las estructuras fúngicas; sin embargo, requiere de la experiencia del observador, ya que en ocasiones pueden ser confundidas con artefactos [34]. La sensibilidad del examen directo se puede incrementar usando fluorocromos como el blanco de calcoflúor, el cual se une a la pared celular de los hongos emitiendo fluorescencia que puede ser detectada con un microscopio de fluorescencia [76,77] (véase figura I).
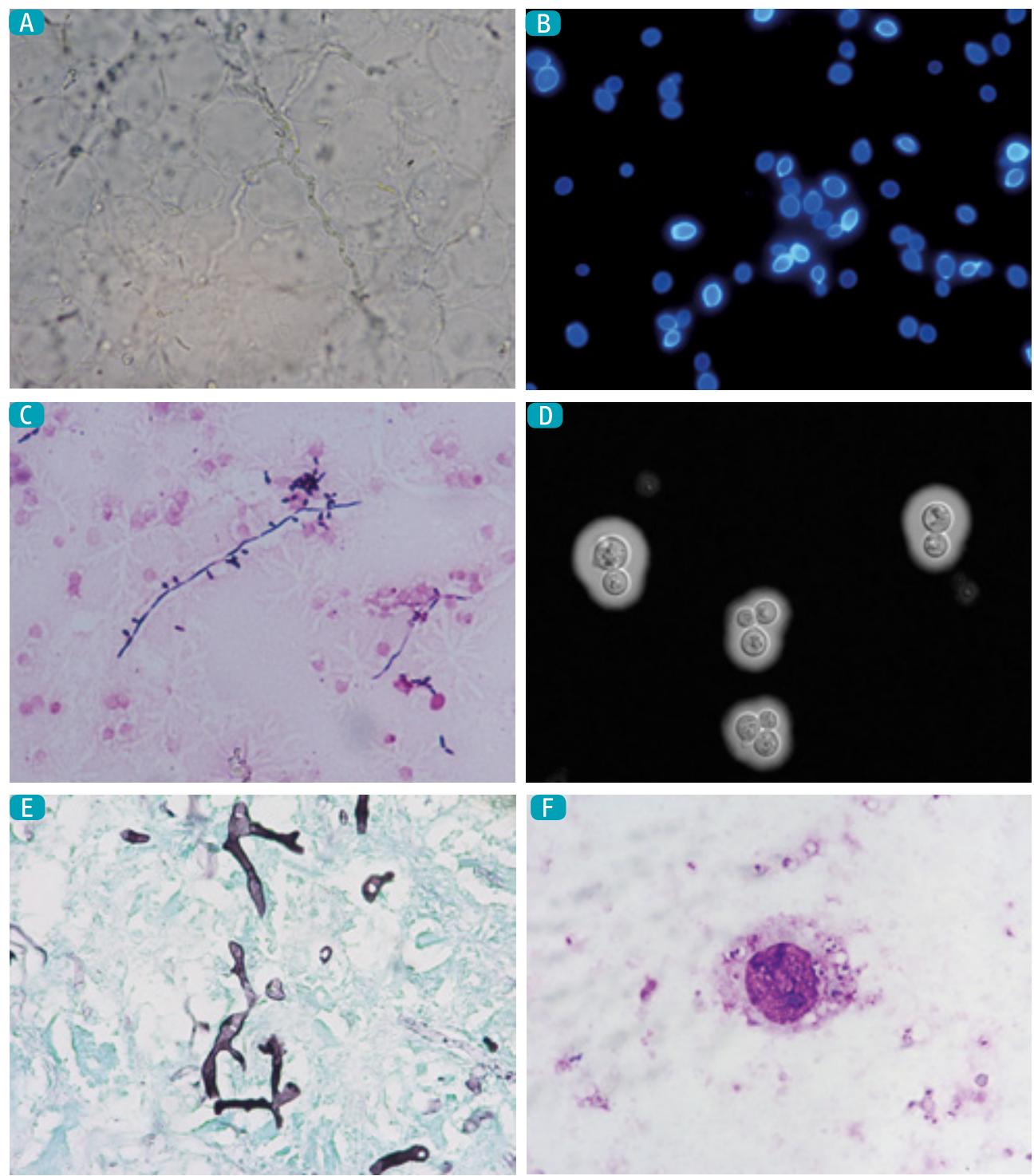

Figura I. Métodos de evaluación microscópica directa de hongos a partir de muestras biológicas. A. Examen directo con $\mathrm{KOH}$. B. Tinción con blanco de calcoflúor. C. Tinción de Gram. D. Examen directo con tinta china. E. Tinción con plata metenamina. F. Tinción de Wright. Cortesía de la Escuela de Microbiología, Universidad de Antioquia. Medellín, Colombia (A, C, E y F) y de las Dras. Cristina Rueda Hernández y Nuria Tevijano Contador, Instituto de Salud Carlos III. España (B y D). 
En los exámenes directos las blastoconidias se observan como estructuras esféricas de diferentes tamaños y tipo de gemación. Por ejemplo, las blastoconidias de Candida spp. tienen un tamaño de $5 \mu \mathrm{m}$ a $10 \mu \mathrm{m}$ de diámetro y son unigemantes, mientras que las de Paracoccidioides brasiliensis varían entre $5 \mu \mathrm{m}$ y $60 \mu \mathrm{m}$ de diámetro y pueden ser multigemantes, en ocasiones tomando una forma descrita como «timón de barco» [34]. Las levaduras también pueden ser encapsuladas como las de Cryptococcus spp. (véase figura ID).

Las hifas se observan como estructuras alargadas, ramificadas o no ramificadas, con presencia de abundantes septos (septadas) o con septos esporádicos (aseptadas), hialinas o dematiáceas (oscuras) según el tipo de hongo filamentoso involucrado en la infección [74]. Por ejemplo la observación de hifas septadas delgadas con ramificaciones dicotómica en ángulo de $45^{\circ}$ sugiere la infección por Aspergillus spp., mientras que la presencia de hifas amplias, irregulares, sin septos o con septos esporádico, en forma de cinta y con ramificaciones en ángulo de $90^{\circ}$ alude la posibilidad de una infección por un hongo del orden Mucorales [34,76,77]. En algunas situaciones es factible la observación de blastoconidias e hifas o pseudohifas en la misma muestra, que sugieren la infección por Candida albicans $[34,76]$. Algunos de los principales hallazgos en los exámenes directos que sugieren la infección micótica se presentan en la tabla 2.

\begin{tabular}{|c|c|c|c|}
\hline Estructura & Hongo & $\begin{array}{l}\text { Tamaño } \\
\text { (diámetro, } \mu \mathrm{m})\end{array}$ & Descripción \\
\hline \multirow[t]{6}{*}{ Blastoconidias } & Histoplasma capsulatum & $2-5$ & $\begin{array}{l}\text { Células pequeñas, de tamaño uniforme, oval o } \\
\text { redondeada, con gemación única. Pueden formar } \\
\text { acúmulos dentro de los macrófagos }\end{array}$ \\
\hline & $\begin{array}{l}\text { Complejo Sporothrix } \\
\text { schenckii }\end{array}$ & $2-6$ & $\begin{array}{l}\text { Cuando se pueden observar son pequeñas, ovales } \\
\text { o redondas, delgadas (en forma de cigarros), con } \\
\text { gemación única y ocasionalmente múltiple }\end{array}$ \\
\hline & Cryptococcus spp. & $2-15$ & $\begin{array}{l}\text { Células de tamaño variable, esféricas con gemación úni- } \\
\text { ca o múltiple e inclusiones citoplasmáticas. Generalmen- } \\
\text { te la cápsula es evidente o se insinúa desde el directo }\end{array}$ \\
\hline & $\begin{array}{l}\text { Malassezia furfur } \\
\text { (en infecciones superficiales) }\end{array}$ & $\begin{array}{l}\text { 3-8 (blastoconidias) } \\
\text { 2,5-4 (hifas) }\end{array}$ & $\begin{array}{l}\text { Hifas cortas y blastoconidias redondas que forman } \\
\text { acúmulos }\end{array}$ \\
\hline & Paracoccidioides brasiliensis & $8-15$ & $\begin{array}{l}\text { De tamaño variable, gemación múltiple, con las } \\
\text { nuevas células más pequeñas }(2-5 \mu \mathrm{m}) \text { rodeando } \\
\text { la células madre en la periferia, adquiriendo una } \\
\text { forma semejante a un «timón de barco» }\end{array}$ \\
\hline & Candida spp. & $5-10$ & $\begin{array}{l}\text { Células redondeadas, con gemación única, en } \\
\text { ocasiones con pseudohifas o hifas dependiendo } \\
\text { de la especie }\end{array}$ \\
\hline $\begin{array}{l}\text { Hifas } \\
\text { aseptadas }\end{array}$ & $\begin{array}{l}\text { Hongos del orden } \\
\text { Mucorales }\end{array}$ & $10-30$ & $\begin{array}{l}\text { Hifas largas, irregulares, en forma de cinta, a } \\
\text { menudo dobladas, pueden encontrarse septos } \\
\text { ocasionales }\end{array}$ \\
\hline \multirow{4}{*}{$\begin{array}{l}\text { Hifas } \\
\text { septadas } \\
\text { hialinas }\end{array}$} & Dermatofitos (en piel y uñas) & $3-15$ & $\begin{array}{l}\text { Hifas septadas hialinas, algunas ramificadas, en } \\
\text { ocasiones con cadenas de artroconidias }\end{array}$ \\
\hline & Dermatofitos (en cabello) & $3-15$ & $\begin{array}{l}\text { Infección ectótrix: artroconidias empaquetadas en } \\
\text { la periferia del pelo } \\
\text { Infección endótrix: artroconidias formadas por la } \\
\text { fragmentación de las hifas en el tallo del cabello }\end{array}$ \\
\hline & Aspergillus spp. & $3-12$ & $\begin{array}{l}\text { Hifas septadas, de tamaño regular, con ramificación } \\
\text { dicotómica en ángulo de } 45^{\circ}\end{array}$ \\
\hline & Fusarium spp. & $3-12$ & $\begin{array}{l}\text { Hifas septadas, de tamaño regular. En ocasiones } \\
\text { se pueden observar hifas dicótomas }\end{array}$ \\
\hline
\end{tabular}




\begin{tabular}{|c|c|c|c|}
\hline $\begin{array}{l}\text { Hifas septadas } \\
\text { dematiáceas }\end{array}$ & $\begin{array}{l}\text { Bipolaris spp. } \\
\text { Cladophialophora spp. } \\
\text { Curvularia spp. } \\
\text { Exophiala spp. } \\
\text { Phialophora spp. } \\
\text { Hortaea werneckii }\end{array}$ & $2-6$ & Hifas dematiáceas polimórficas \\
\hline $\begin{array}{l}\text { Cuerpos } \\
\text { escleróticos }\end{array}$ & $\begin{array}{l}\text { Cladophialophora carrionii } \\
\text { Fonsecaea pedrosoi } \\
\text { Fonsecaea compacta } \\
\text { Phialophora verrucosa } \\
\text { Rhinocladiella aquaspersa }\end{array}$ & $5-20$ & $\begin{array}{l}\text { Estructuras color marrón, redondeadas o polimór- } \\
\text { ficas, de pared gruesa con septos transversales, que } \\
\text { contienen dos planos de fisión que forman una } \\
\text { tétrada de células (células escleróticas de Medlar) }\end{array}$ \\
\hline \multirow{9}{*}{$\begin{array}{l}\text { Gránulos } \\
\text { (micetoma) }\end{array}$} & Acremonium spp. & $200-300$ & \multirow[t]{4}{*}{ Gránulos suaves de color blanco } \\
\hline & $\begin{array}{l}\text { Curvularia geniculata } \\
\text { Curvularia lunata }\end{array}$ & $65-160$ & \\
\hline & Fusarium moniliforme & $200-500$ & \\
\hline & Fusarium solani & $300-600$ & \\
\hline & Aspergillus nidulans & $500-1000$ & Gránulos duros de color negro \\
\hline & Exophiala jeanselmei & $200-300$ & $\begin{array}{l}\text { Gránulos suaves de color negro con vacuolas, } \\
\text { formado por hifas oscuras }\end{array}$ \\
\hline & Madurella grisea & $350-500$ & \multirow[t]{2}{*}{ Gránulos duros de color marrón a negro } \\
\hline & Madurella mycetomatis & $200-900$ & \\
\hline & Pseudallescheria boydii & $200-300$ & $\begin{array}{l}\text { Gránulos suaves de color blanco, compuestos por } \\
\text { hifas y células hinchadas en la periferia }\end{array}$ \\
\hline
\end{tabular}

Las preparaciones también pueden ser teñidas con las coloraciones de Wright, Giemsa o Gram dependiendo del tipo de muestra; por ejemplo, la tinción de Gram, utilizada comúnmente para la detección de bacterias, es de ayuda diagnóstica en las infecciones micóticas de las mucosas oral o vaginal, donde los hongos se observan generalmente Gram positivos. Asimismo, las tinciones de Giemsa o Wright pueden facilitar la observación de levaduras intracelulares de Histoplasma capsulatum en extendidos de sangre, médula ósea o esputo [34,76]. El tratamiento con tinta china o nigrosina de las muestras de pacientes con sospecha de criptococosis, principalmente líquido cefalorraquídeo, facilitan la observación de las levaduras encapsuladas [76,77] (véase figura I).

Por su parte, las preparaciones histopatológicas apoyan el diagnóstico de las infecciones fúngicas invasivas. Específicamente, la tinción con hematoxilina-eosina, además de permitir la identificación de levaduras y hongos filamentosos en tejido, ayuda a identificar la reacción inflamatoria en el hospedero como presencia de células gigantes multinucleadas, material necrótico, hemorragia y el fenómeno de Splendore-Höeppli. La plata metenamina (GomoriGrocott) se considera de gran utilidad para la detección de hongos en tejido debido a que resalta la pared fúngica en color café o negro en medio del tejido que toma un color verde. Finalmente, el ácido peryódico de Schiff (PAS), dada la afinidad que tiene por los polisacáridos de la pared de los hongos, permite distinguir las hifas y las blastoconidias del tejido. Otras coloraciones más específicas como la de Fontana-Masson y la mucicarmín de Mayer son útiles en la identificación de melanina en la pared fúngica y de mucopolisacáridos capsulares, respectivamente $[34,78]$. 
La sensibilidad de la microscopía para el diagnóstico de la infección por hongos es baja y varía según el agente causal y la cantidad en que se encuentre, el tipo y la calidad de la muestra, y la preparación y experiencia del profesional del laboratorio encargado del análisis [79,80]. Por tal razón, es importante considerar que un examen microscópico negativo no excluye la infección micótica. Por otro lado, este examen no es específico debido a que algunas estructuras o artefactos pueden confundirse fácilmente con elementos fúngicos. Además, con estos métodos no es factible la identificación del agente causal [74].

\section{Pruebas inmunológicas}

Considerando la baja sensibilidad y especificidad de las técnicas convencionales (directos y cultivo) en el diagnóstico micológico, la detección de antígenos y anticuerpos se han incluido en la batería de pruebas para el diagnóstico de diferentes micosis.

\section{Detección de anticuerpos}

Históricamente las pruebas más utilizadas en el laboratorio de rutina para la detección de anticuerpos son la inmunodifusión doble de Ouchterlony, la fijación de complemento y los inmunoensayos enzimáticos (ELISA; del inglés, Enzyme Linked Immuno Sorbent Assay) [8I]. La prueba de inmunodifusión se basa en la difusión radial de los inmunoreactantes (antígenos y anticuerpos) en un gel de agar que, al encontrarse, forman un complejo antígenoanticuerpo que se precipita en el gel y se visualiza como una línea blanquecina. Esta técnica se ha utilizado para el diagnóstico del aspergiloma, la aspergilosis pulmonar crónica, la aspergilosis broncopulmonar alérgica, la histoplasmosis, la paracoccidioidomicosis y la esporotricosis. Además, se ha empleado de forma exitosa en estudios epidemiológicos [82-84].

Por su parte, la prueba de fijación de complemento se basa en la capacidad del complemento para unirse a los complejos antígeno-anticuerpo, determinada por la lisis de eritrocitos. Esta prueba ha sido de utilidad en la detección de anticuerpos contra Histoplasma capsulatum y Paracoccidioides brasiliensis; sin embargo, su uso de rutina es poco práctico debido a que es una técnica laboriosa. Una de las pruebas comerciales formato ELISA más conocida para la detección de anticuerpos es Platelia ${ }^{\mathrm{TM}}$ Candida Ab (Bio-Rad Laboratories, California, Estados Unidos), la cual detecta anticuerpos circulantes contra el manano de Candida spp. y es de ayuda en el diagnóstico de la candidemia y de la candidiasis invasiva $[85,86]$.

La sensibilidad y especificidad de las pruebas que detectan anticuerpos son variables y la interpretación de los resultados se debe hacer con cuidado. Con el fin de mejorar estas pruebas se ha tratado de desarrollar otras con formato ELISA que utilizan antígenos purificados o recombinantes fúngicos para la detección de anticuerpos circulantes en el paciente, lo que puede disminuir o eliminar las reacciones cruzadas de las técnicas anteriores $[82,87,88]$. Otras desventaja de la detección de anticuerpos es que suele ser útil en pacientes inmunocompetentes, más no en los inmunocomprometidos [78,82,87,89].

\section{Detección de antígenos (biomarcadores)}

La detección y cuantificación de biomarcadores como el galactomanano, el cual hace parte de la pared celular fúngica principalmente de las especies de Aspergillus, y del 1,3- $\beta$-D-glucano, 
presente en varios hongos patógenos (panfúngica) apoyan el diagnóstico de algunas infecciones fúngicas invasivas. Estos antígenos se pueden detectar en muestras clínicas como suero y lavado broncoalveolar [90]. Entre los estuches comerciales en el formato ELISA disponibles para la detección de estos antígenos se encuentran Platelia ${ }^{\text {TM }}$ Aspergillus EIA (Bio-Rad Laboratories, California, Estados Unidos), Fungitell ${ }^{\circledR} \beta$-D-Glucan Assay (Associates of Cape Cod Inc, Massachusetts, Estados Unidos) y Fungitec G Test MK (Seikagaku Biobusiness, Tokio, Japón). También se puede detectar el manano, un componente de la pared celular de Candida spp. (Platelia ${ }^{\mathrm{TM}}$ Candida Ag, Bio-Rad Laboratories) como ayuda en el diagnóstico de candidemia y candidiasis invasiva $[85,86]$.

La sensibilidad y especificidad de estas pruebas son variables, presentan falsos positivos y requieren determinaciones seriadas, en algunos casos, para mejorar la sensibilidad [91,92]. Incluso, aún existen controversias con respecto a la utilidad diagnóstica de estas pruebas [72,93]. La detección del polisacárido de la cápsula de Cryptococcus neoformans por aglutinación con partículas de látex es una prueba ampliamente utilizada en el diagnóstico de la criptococosis, debido a su sensibilidad y especificidad tanto en muestras de líquido cefalorraquídeo como de suero $(>90 \%)[94,95]$.

Recientemente se ha desarrollado una técnica para detectar antígenos de las especies de Aspergillus en suero y lavado broncoalveolar de pacientes con aspergilosis invasiva, el Lateral Flow devices, el cual corresponde a una inmunocromatografía en la que se utiliza un anticuerpo específico dirigido contra una glicoproteína extracelular, secretada por el hongo durante el crecimiento activo de la hifa [96]. Esta es una técnica rápida y sensible por lo que se le atribuye un alto valor diagnóstico, principalmente en los pacientes inmunocomprometidos con riesgo de desarrollar aspergilosis invasiva [97]. Además, se considera una técnica sencilla, de fácil manejo en el laboratorio de rutina, que no requiere personal especializado y con la que se obtienen resultados rápidos [98]. De igual manera, se han diseñado variaciones de esta técnica para la detección de un antígeno capsular de Cryptococcus neoformans en suero y líquido cefalorraquídeo [8I].

La detección de compuestos orgánicos volátiles (metabolitos secundarios) de Aspergillus spp., en el aire exhalado de los pacientes infectados, se plantea como una opción para el diagnóstico de la aspergilosis pulmonar. Los metabolitos se detectan usando la técnica de cromatografía de gases acoplada con espectrometría de masas o las narices electrónicas (del inglés, electronic noses). La sensibilidad y especificidad de las pruebas se calculó entre el $83,3 \%$ y el $100 \%$, y entre el $94 \%$ y el $93,3 \%$, respectivamente $[99,100]$. A pesar de lo prometedor que parecen ser los resultados de las técnicas, es necesario llevar a cabo estudios posteriores con el fin de evaluar la influencia que pueden tener factores como el tratamiento con antimicóticos $u$ otros medicamentos, o la presencia de otros microorganismos en los resultados para definir el valor diagnóstico real de las mismas. Además, es importante analizar el costo-efectividad de esta prueba $[93,101]$.

\section{Identificación del agente causal}

La identificación precisa del agente causal de una infección micótica (en lo posible hasta género y especie) tiene gran importancia en términos de la predicción del curso de la infección, el órgano blanco y la susceptibilidad antifúngica [72]. El método convencional y de referencia, 
hasta el momento, para la identificación fúngica se basa en el aislamiento del hongo in vitro a partir de muestras biológicas [80]. Otros criterios bioquímicos y fisiológicos, así como la termotolerancia y el dimorfismo, suelen complementar la identificación [34,76]. A continuación se hará alusión al procedimiento básico a seguir para el cultivo de muestras de pacientes con sospecha de una micosis.

\section{Cultivo de muestras biológicas para el aislamiento de hongos patógenos}

Dado que los requerimientos de cada hongo para su crecimiento son diferentes, las muestras clínicas deben ser cultivadas en varios medios sólidos. Los más utilizados son el Agar Sabouraud Dextrosa y el Agar Papa Dextrosa (PDA), los cuales permiten la recuperación primaria de hongos patógenos no exigentes y favorecen la esporulación. Otro medio utilizado es el Agar Micosel, el cual contiene cicloheximida y cloranfenicol para inhibir el crecimiento de hongos ambientales y de bacterias, respectivamente. El agar infusión de cerebro y corazón $(\mathrm{BHI})$, al ser un medio no selectivo, permite el crecimiento de la mayoría de los hongos clínicamente relevantes [76]. En el caso de sospecha de enfermedad fúngica invasiva es común el uso de hemocultivos en botellas bifásicas con $\mathrm{BHI}$ para los cuales se cuenta actualmente con sistemas automatizados, principalmente para la detección de levaduras, como el sistema BACTECTM (Becton Dickinson, Nueva Jersey, Estados Unidos), BacT/ALERT ${ }^{\circledR}$ (BioMérieux, Marcy-l'Étoile, Francia) y VersaTREK ${ }^{\circledR}$ (Thermo Scientific, Massachusetts, Estados Unidos).

Otros medios, como los agares cromogénicos diferenciales permiten, además del aislamiento de las levaduras, la identificación presuntiva de algunas de las especies de Candida y de otras levaduras, que se pueden encontrar únicas o de forma simultánea en una misma muestra. El fundamento de estos medios se basa en la inclusión de sustratos que, ante la presencia de una actividad enzimática específica, produce un color determinado dependiendo de la levadura aislada. En la práctica clínica estos medios se utilizan principalmente para identificar la presencia de levaduras en muestras de orina $[34,72,74]$, siendo el más utilizado de ellos el CHROMagarTM (BD, Carolina del Norte, Estados Unidos). En ciertas situaciones, puede estar indicada la utilización de medios específicos para el aislamiento de determinados hongos como Malassezia spp. (p. ej. agar Dixon), Cryptococcus spp.(p. ej. Agar con L-Dopa o Agar semilla de girasol) u hongos dimórficos patógenos primarios ( $p$. ej. $\mathrm{BHI}$ ), al igual que medios de cultivo diferenciales o que induzcan la esporulación ( $p$. ej. agar arroz o el PDA) [34,74].

Para la realización del cultivo a partir de muestras superficiales se recomienda realizar entre ocho y 12 sitios de siembra con un bisturí o un asa micológica haciendo incisiones sobre el agar. Las muestras de tejido deben ser procesadas (maceradas, cortadas o digeridas) y las de líquidos estériles concentradas por centrifugación antes de ser cultivadas; luego, se adiciona al menos I $\mathrm{mL}$ de la muestra y se esparce por toda la superficie del medio de cultivo. Las muestras de médula ósea se depositan directamente en el medio de cultivo. Las muestras de orina deben ser procesadas y cultivadas inmediatamente después de la recolección (se suele cultivar el sedimento obtenido por centrifugación) [34]. Las muestras procedentes del sistema respiratorio (esputo o lavado broncoalveolar) deben ser digeridas para eliminar los detritus [ I I] y proce- 
der a cultivarlas por siembra bacteriológica o siembra cuantitativa, como se indica para las muestras de orina.

En la tabla 3 se indican los hongos patógenos más frecuentemente aislados de los diferentes tipos de muestras clínicas

Teniendo en cuenta la variación en la temperatura óptima de crecimiento de los hongos patógenos se recomienda incubar los cultivos a $25{ }^{\circ} \mathrm{C}-30{ }^{\circ} \mathrm{C}$ y a $37{ }^{\circ} \mathrm{C}$ durante varias semanas (generalmente entre cuatro y seis, incluso hasta por 12) [1 1,76]. Los cultivos no se deben descartar sin completar el período de incubación, aun cuando ya se haya aislado un posible patógeno, ya que puede tratarse de un contaminante que impide el crecimiento del verdadero agente causal. La interpretación del resultado de los cultivos siempre se debe basar en el cuadro clínico del paciente. El aislamiento de un hongo patógeno primario en muestras estériles (p. ej. biopsias, líquido cefalorraquídeo y otros líquidos biológicos) se considera siempre de valor diagnóstico. Por el contrario, el aislamiento en muestras de esputo y lavado broncoalveolar siempre plantea una gran dificultad de interpretación debido a la alta contaminación de la muestra, por ejemplo, Candida spp., al ser parte de la microbiota del tracto respiratorio se considera que no es el agente causal de infecciones respiratorias a pesar de ser aislada en el cultivo [34,74].

La mayoría de los hongos oportunistas son ubicuos, por tanto, la interpretación de un cultivo positivo debe considerar la posible contaminación en el sitio de la toma de las muestras, durante el transporte de las muestras o debido a la manipulación de la muestra en el laboratorio de microbiología.

Por esto, la presencia de hifas en el examen directo de la muestra, el crecimiento de colonias con las mismas características en diferentes medios, en los sitos de inoculación y a partir de muestras del mismo paciente tomadas en diferentes momentos, así como el crecimiento del microorganismo a $35^{\circ} \mathrm{C}-37^{\circ} \mathrm{C}$ (si la sospecha es de una infección invasiva o diseminada), sugiere una infección fúngica [77].

\section{Tabla 3. Hongos frecuentemente aislados a} partir de muestras clínicas

\begin{tabular}{|c|c|}
\hline Muestra & Hongos \\
\hline Sangre & $\begin{array}{l}\text { Complejo Candida albicans } \\
\text { Candida tropicalis } \\
\text { Complejo Candida parapsilosis } \\
\text { Cryptococcus spp. } \\
\text { Histoplasma capsulatum } \\
\text { Candida lusitaniae } \\
\text { Candida kefyr }\end{array}$ \\
\hline $\begin{array}{l}\text { Líquido } \\
\text { cefalorraquídeo }\end{array}$ & Cryptococcus neoformans \\
\hline $\begin{array}{l}\text { Tracto } \\
\text { genito-urinario }\end{array}$ & $\begin{array}{l}\text { Complejo Candida albicans } \\
\text { Complejo Candida glabrata } \\
\text { Candida tropicalis } \\
\text { Candida krusei } \\
\text { Cryptococcus spp. } \\
\text { Saccharomyces spp. } \\
\text { Histoplasma capsulatum }\end{array}$ \\
\hline $\begin{array}{l}\text { Tracto } \\
\text { respiratorio }\end{array}$ & $\begin{array}{l}\text { Paracoccidioides brasiliensis } \\
\text { Histoplasma capsulatum } \\
\text { Aspergillus spp. } \\
\text { Cladophialophora spp. } \\
\text { Fusarium spp. } \\
\text { Mucorales (poco frecuente) }\end{array}$ \\
\hline $\begin{array}{l}\text { Piel superficial } \\
\text { y anexos (uñas } \\
\text { y pelo) }\end{array}$ & $\begin{array}{l}\text { Trichophyton rubrum } \\
\text { Trichophyton interdigitale (mentagro- } \\
\text { phytes) } \\
\text { Complejo Candida albicans } \\
\text { Epydermophyton floccosum } \\
\text { Candida parapsilosis } \\
\text { Malassezia spp. } \\
\text { Microsporum canis } \\
\text { Microsporum gypseum } \\
\text { Aspergillus spp. } \\
\text { Fusarium spp. } \\
\text { Neoscytalidium dimidiatum }\end{array}$ \\
\hline $\begin{array}{l}\text { Piel y tejido ce- } \\
\text { lular subcutáneo }\end{array}$ & $\begin{array}{l}\text { Complejo Sporothrix schenckii } \\
\text { Fonsecaea pedrosoi } \\
\text { Alternaria spp. } \\
\text { Acremonium spp. } \\
\text { Phialophora spp. } \\
\text { Basidiobolus spp. } \\
\text { Conidiobolus spp. } \\
\text { Curvularia spp. } \\
\text { Exophiala spp. } \\
\text { Pseudallescheria boydii } \\
\text { Rhinocladiella aquaspersa } \\
\text { Mucorales (poco frecuente) }\end{array}$ \\
\hline
\end{tabular}

Tomado y modificado de Overview of Fungal Identification Methods and Strategies (p. 726) en: Bailey \& Scott's Diagnostic Microbiology, por P.M. Tille, 20 14, Misuri, Estados Unidos: Elsevier Mosby. Copyright 2014 por Mosby, Inc. [34] 
La identificación del hongo se realiza mediante la determinación de las características macroscópicas de las colonias en el cultivo como es el color (del anverso y el reverso), la forma (p. ej. rugosa o lisa) y la textura (p. ej. algodonosa, aterciopelada, glabra, cremosa, viscosa o pastosa) (véase figura 2) [34]. El tiempo de crecimiento es un factor que puede dar indicios del tipo de hongo aislado. Por ejemplo, un crecimiento entre 24 h y 48 h de incubación probablemente corresponde a una levadura. Entretanto, el tiempo de crecimiento y esporulación de los hongos filamentosos es variable y puede comprender desde uno o dos días, tal como sucede con los del orden Mucorales, hasta dos semanas en el caso de los dermatofitos, otros hongos hialinos y los hongos dematiáceos, o hasta cuatro como sucede con Histoplasma capsulatum y Paracoccidioides brasiliensis [34,76] (véase tabla 4).

A

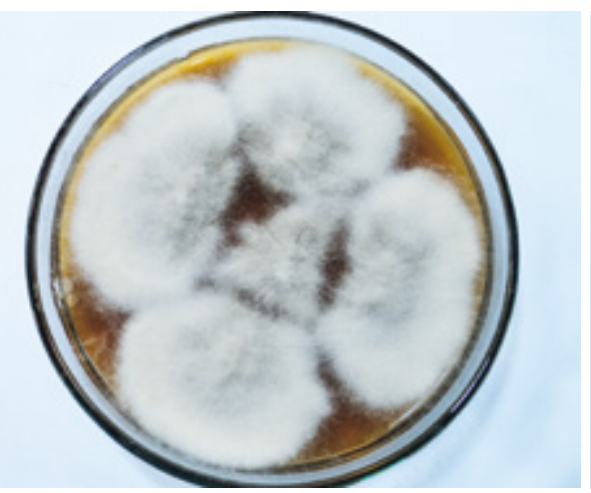

B

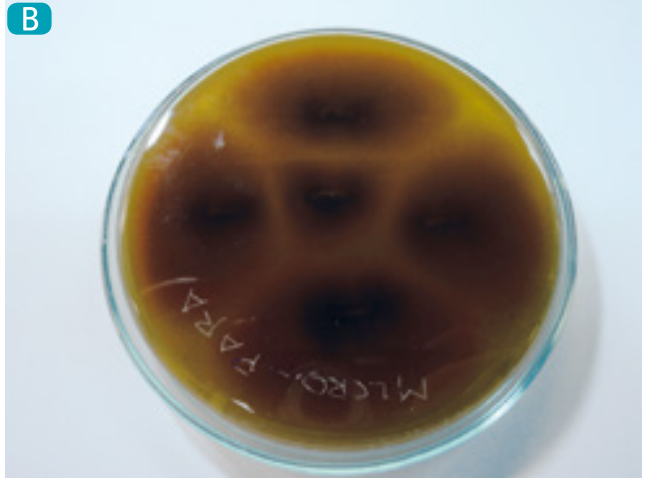

Figura 2. Apariencia de las colonias de un cultivo de Fusarium spp. en el anverso (A) y el reverso (B). Obsérvese la textura, la forma y el pigmento de la colonia. Cortesía de la Escuela de Microbiología, Universidad de Antioquia. Medellín, Colombia.

Posterior al crecimiento visible del hongo en el cultivo se determinan sus características microscópicas. Para esto, se realizan preparaciones en un portaobjetos mezclando una gota de azul de lactofenol con una porción de las colonias tomada con cinta transparente o mediante pequeños cortes con bisturí o asa micológica en el borde de crecimiento de las colonias [34]. La observación microscópica permite la identificación del hongo mediante la detección de las estructuras características como blastoconidias, hifas, pseudohifas, artroconidias, algunas estructuras especializadas como conidias (macro y micro), células conidiógenas, clamidoconidias, esporangias y esporangióforos, ascas, ascosporas y picnidios [1 1,34, 102] (véanse tabla 4 y figura 3).

La identificación a partir de un cultivo puede complementarse evaluando la termotolerancia, definida como la capacidad de un microorganismo para crecer a temperaturas mayores de $35^{\circ} \mathrm{C}$, lo que representa una ventaja selectiva para adaptarse al ambiente del hospedero y causar infección [103-106]. Para confirmar la termotolerancia de un hongo se realizan varios cultivos que se incuban a diferentes temperaturas (p. ej. $25^{\circ} \mathrm{C}, 30^{\circ} \mathrm{C}, 35^{\circ} \mathrm{C}, 37^{\circ} \mathrm{C}$ y $42^{\circ} \mathrm{C}$ ) y se va observando periódicamente su crecimiento, el cual en caso de presentarse indica la capacidad de adaptación del hongo y de soportar la temperatura fisiológica humana o superior, como en los casos de fiebre y, por lo tanto, de ser patógeno. 
Tabla 4. Principales características macroscópicas y microscópicas de los hongos patógenos más importantes

Morfología de la colonia
Colonias de aspecto liso, cremoso, viscoso o
pastoso

Morfología

microscópica

Blastoconidias

y pseudohifas

Blastoconidias solas

Hifas y artroconidias

Colonias de superficie blanco, crema o gris claro, Microconidias con o sin macroconidias reverso no pigmentado

\section{Posible hongo (género) \\ Candida \\ Candida \\ (principalmente Candida glabrata) \\ Cryptococcus \\ Malassezia \\ Saccharomyces \\ Geotrichum \\ Trichosporon}

Dermatofitos

Epidermophyton

Microsporum

Trichophyton

Ambientales

Acremonium

Fusarium

Pseudasllescheria

Sepedonium

Con esporangias o esporangiolas

Rhizopus

Mucor

Absidia

Cunninghamella

Rhizomucor

Syncephalastrum

Con artroconidias

Geotrichum

Coccidiodes

Hifas con clamidoconidias

Dermatofitos:

Epidermophyton

Microsporum

Trichophyton

Dermatofitos:

Microsporum

Trichophyton

Ambientales:

Acremonium

Colonias de superficie crema, blanco, beige o Hifas y conidias gris claro, con reverso rojo y violeta

Dermatofitos:

Microsporum

Trichophyton

Ambientales:

Penicillium

Colonias de superficie crema, blanco, beige o Hifas y conidias gris claro, con reverso marrón

Dermatofitos:

Microsporum

Trichophyton

Ambientales:

Madurella

Scopulariopsis

Colonias de superficie crema, blanco, beige o Hifas y conidias

Ambientales:

Nigrospora

Phoma

Pseudallescheria

Scedosporium 
Dermatofitos:

Trichophyton

Ambientales:

Aspergillus

Cladophialophora

Phialophora

Macronidias

Dermatofitos:

Epidermophyton

Microsporum

Trichophyton

Ambientales:

Alternaria

Bipolaris

Botrytis

Curvularia

Esporangias

Rhizomucor

Rhizopus

Colonias de superficie amarilla a naranja

Hifas y conidias

Dermatofitos:

Epidermophyton

Microsporum

Trichophyton

Ambientales:

Aspergillus

Penicillium

Sepedonium

Verticillium

Colonias de superficie rosa a violeta

Hifas y conidias

Dermatofitos:

Microsporum

Trichophyton

Ambientales:

Acremonium

Aspergillus

Fusarium

Paecilomyces

Verticillium

Colonias de superficie verde y reverso claro

Colonias de superficie gris a negra, reverso claro

Colonias de superficie verde, gris oscuro negro; reverso oscuro
Hifas y conidias
Ambientales:

Aspergillus

Penicillium

Trichoderma

(contaminante)

Verticillium

Hifas y conidias

Esporangióforos con merosporangias alrededor de la vesícula

Conidias pequeñas

Aspergillus

Syncephalastrum

Cladosporium/

Cladophialophora

Exophiala

Fonsecaea

Phialophora

Pseudallescheria

Scedosporium

Conidias grandes

Bipolaris

Curvularia

Nigrospora

Ulocladium

Solo hifas con o sin clamidoconidias

Madurella 


\begin{tabular}{|c|c|c|}
\hline \multirow[t]{2}{*}{$\begin{array}{l}\text { Colonias blancas, de crecimiento lento y micelio } \\
\text { corto }\end{array}$} & $\begin{array}{l}\text { Hifas, microconidias y macroconidias } \\
\text { tuberculadas }\end{array}$ & Histoplasma \\
\hline & $\begin{array}{l}\text { Microconidias } \\
\text { pedunculadas }\end{array}$ & Paracoccidioides \\
\hline $\begin{array}{l}\text { Colonias con aspecto arrugado blancas, crema, } \\
\text { marrón, negras o combinadas }\end{array}$ & $\begin{array}{l}\text { Hifas delgadas y conidias ovoides emer- } \\
\text { giendo de forma simpodial alrededor del } \\
\text { extremo de un conidióforo (semejando } \\
\text { una margarita) }\end{array}$ & Sporothrix \\
\hline
\end{tabular}

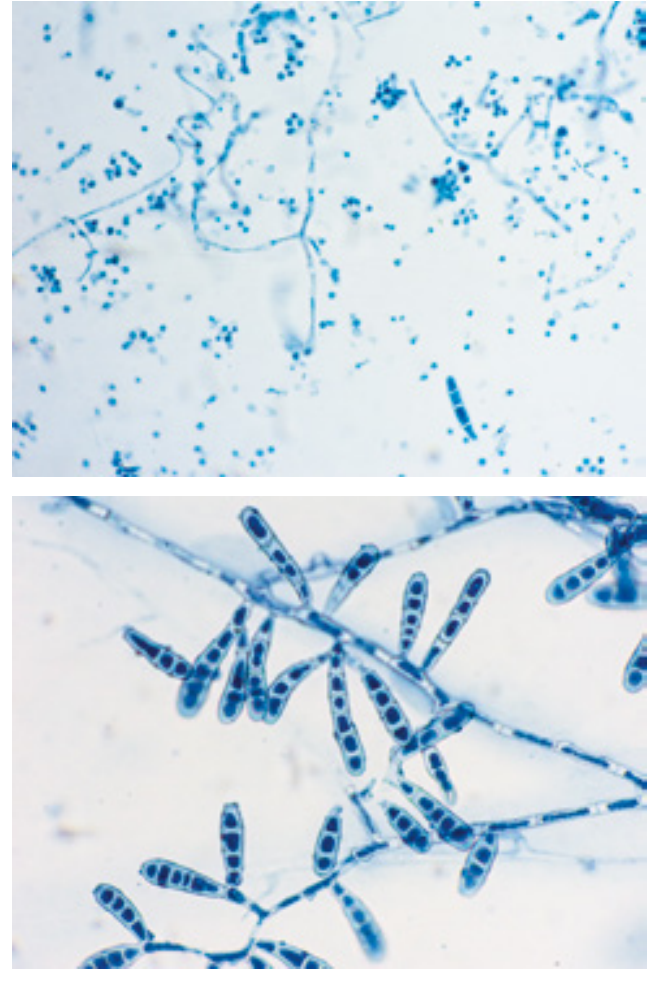

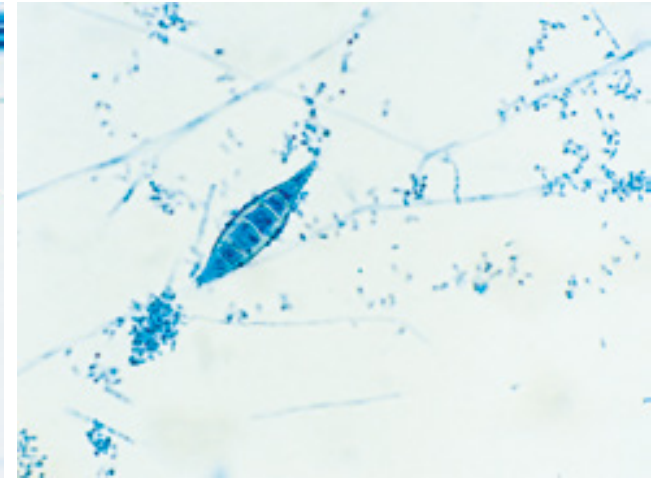

Figura 3. Características microscópicas observadas en preparaciones con azul de lactofenol a partir de colonias de dermatofitos. A. Microconidias, hifas, hifas en espiral (flecha punteada)y macroconidias (flecha sólida) B. Hifas, macro y microconidias. C. Hifas y macroconidias, y ausencia de microconidias. Cortesía de la Escuela de Microbiología, Universidad de Antioquia.

Otro factor que puede ayudar en la identificación de un hongo es el dimorfismo. Este es un factor de virulencia presente en algunos hongos, que consiste en la capacidad de transformarse de una forma micelial a la de levadura en respuesta a cambios de temperatura, nutrientes o concentración de dióxido de carbono, lo que facilita la supervivencia en los tejidos del hospedero. Algunas de las especies fúngicas que tienen esta cualidad son Blastomyces dermatitidis, Histoplasma capsulatum, Paracoccidioides blasiliensis y las especies del complejo Sporothrix schenckii. Estos hongos se encuentran en el ambiente en su forma micelial y pueden ser aislados en esta misma forma en cultivos incubados a una temperatura entre $25^{\circ} \mathrm{C}$ y $30^{\circ} \mathrm{C}$. La reversión a la forma de levadura ocurre, generalmente, en cultivos incubados a una temperatura de $35^{\circ} \mathrm{C}$, en medios como el agar infusión de cerebro y corazón $(\mathrm{BH})$ o el agar sangre, en presencia de $\mathrm{CO}_{2}$, condiciones que pueden semejarse a las encontradas en el hospedero [107].

Las pruebas bioquímicas como la asimilación de carbono o de nitrógeno y la fermentación de carbohidratos también pueden apoyar la información de un microorganismo aislado. La 
capacidad de un microorganismo para utilizar o no un sustrato es revelada por el cambio de color en el medio, por la producción de gas o por turbidez [108]. Estas pruebas se encuentran disponibles como estuches comerciales (p. ej. el API 20 C de BioMérieux, Marcy-l'Étoile, Francia) o en dispositivos automatizados (p. ej. sistema VITEK ${ }^{\circledR}$, BioMérieux) para evaluar las propiedades mencionadas en levaduras [72]. Otras pruebas como la inducción de la formación del tubo germinal y la formación de clamidosporas en agar arroz ayudan a la identificación de algunas especies de Candida [72].

No obstante, las características fenotípicas referidas pueden verse afectadas por factores inherentes a cada hongo como es el crecimiento lento de algunos de ellos, los requerimientos nutricionales que impiden el crecimiento en los medios convencionales y la termotolerancia, entre otros. En algunos casos no se logra fácilmente la observación de las estructuras características debido a la dificultad para lograr la esporulación del hongo. Además, entre especies o incluso entre géneros de algunos hongos existe una estrecha similitud morfológica que hace difícil su identificación. Un ejemplo de ello se presenta con el hongo patógeno Histoplasma capsulatum que comparte características macroscópicas y microscópicas con hongos ambientales que, además de ser contaminantes, pueden ser patógenos, como es el caso de Chrysosporium spp. y Sepedonium spp. [102].

Un inconveniente adicional en la identificación de hongos de importancia médica es el cambio en el panorama epidemiológico de estas infecciones, puesto que han emergido hongos que no se habían reconocido como patógenos humanos [109]. Además, a la fecha, algunos hongos como Lacazia loboi y Pneumocystis jirovecii no se han logrado cultivar en el laboratorio [ I l 0,1 l I ].

\section{Métodos moleculares para la identificación de hongos de importancia médica}

En la lucha contra las enfermedades infecciosas, la microbiología clínica ha requerido optimizar a nivel de especificidad, sensibilidad, rapidez y confianza las pruebas diagnósticas para contribuir a la prevención, el control y al tratamiento de estas enfermedades. Con el fin de obviar las limitaciones de los exámenes directos, las coloraciones y las pruebas antigénicas, y como alternativa a la identificación de aislamientos fúngicos por características fenotípicas, se han desarrollado diferentes métodos moleculares que han permitido el acceso a secuencias de ADN y a los perfiles proteicos del hongo, siendo posiblemente más promisorias en cuanto a sensibilidad y especificidad.

Entre las técnicas moleculares utilizadas en la identificación de hongos se han descrito: el análisis de la longitud de los fragmentos de restricción (RFLP; del inglés, Restriction Fragment Length Polymorphism), la electroforesis de enzimas multilocus (MLEE; del inglés, Multilocus Enzyme Electrophoresis), el uso de sondas de hibridación marcadas para la identificación de un fragmento específico de ADN (hibridación Southern o Southern blot) y la reacción en cadena de la polimerasa (PCR, del inglés, Polymerase Chain Reaction) y sus modificaciones, para la amplificación de diferentes fragmentos de ADN específicos $[1 \mid 2,1$ 13].

La amplificación de dianas acoplada a la secuenciación de los productos amplificados ha permitido una identificación más precisa de diferentes hongos, tanto directamente de 
muestras clínicas como a partir de cultivos [1 | 4] En la última década, diferentes trabajos han mostrado la utilidad del MALDI-TOF (del inglés, Matrix-Assisted Laser Desorption/ Ionization-Time-of-Flight) para la identificación de hongos a partir de muestras clínicas y de cultivos [1 15]. A continuación nos referiremos brevemente a las técnicas moleculares más utilizadas en el diagnóstico micológico como son las basadas en el formato PCR y la tecnología MALDI-TOF.

\section{Detección del ADN fúngico por reacción en cadena de la polimerasa}

Entre las nuevas aplicaciones para la identificación de hongos a partir de muestras clínicas se encuentran la reacción en cadena de la polimerasa (PCR). Inicialmente se utilizó el formato convencional de esta técnica para amplificar un solo fragmento específico de ADN. Las dianas más utilizadas con este propósito corresponden a secuencias o fragmentos de genes que codifican para la actina, la calmodulina, la $\beta$-tubulina, los genes ribosomales $5.8 \mathrm{~S}$, I 8S y 28S, el factor de elongación I - $\alpha$ y las regiones no codificantes ITSI e ITS2 (del inglés, Internal Transcribed Spacer) del ADN ribosomal. Estas técnicas sirven tanto para identificar hongos a partir de muestras clínicas (suero, sangre o muestra de tejido embebidas en parafina) como de cultivos [53, I I 2, I I 6, I I 7]. En la figura 4 se muestra el producto de la amplificación de las secuencias ITS de cuatro hongos filamentosos separados por electroforesis en un gel de agarosa.

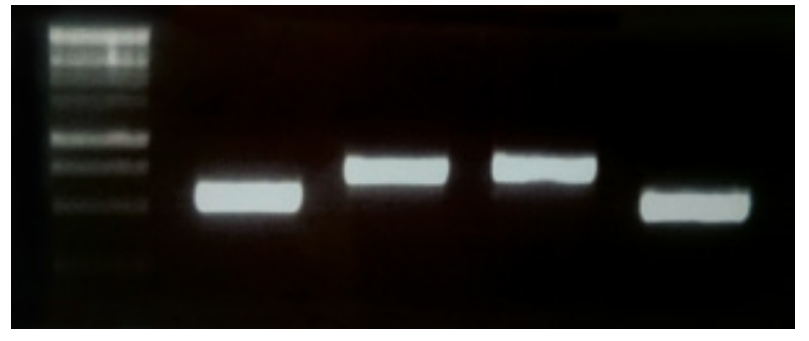

Figura 4. Electroforesis en gel de agarosa en el que se observan los productos de amplificación de secuencias ITS obtenidas a partir del ADN de cuatro hongos filamentosos (Carriles 2, 3, 4 y 5). Marcador de peso molecular (Carril I). Cortesía del Laboratorio de Micología, Instituto de Salud Carlos III. España.

La reacción en cadena de la polimerasa a pesar de ser sensible presenta desventajas para su implementación en la práctica clínica debido a los falsos positivos, a que no es una técnica cuantitativa y a que la obtención del ADN a partir de las muestras clínicas es complicada y el rendimiento es variable [ 1 | 8]. Tratando de superar a la reacción en cadena de la polimerasa (PCR) convencional diferentes variaciones han sido introducidas dando como resultado técnicas como la PCR-ELISA, la PCR anidada y la PCR cuantitativa, conocida también como PCR en tiempo real. En esta última variación la cuantificación de la fluorescencia emitida durante cada ciclo es proporcional a la cantidad de ADN que se está amplificando, el cual es indicativo de la carga fúngica [ 1 | 8]. En numerosos estudios se ha utilizado este método con fines diagnósticos de las infecciones fúngicas a partir de diferentes muestras clínicas [ I 18-123]. La PCR en tiempo real es más robusta, específica y sensible que la PCR convencional; además, demanda menos cantidad de ADN en las muestras [ $[18,121]$.

Una variación de la reacción en cadena de la polimerasa cuantitativa es la PCR en tiempo real multiplex, la cual puede detectar de forma simultánea múltiples fragmentos de ADN en una sola reacción, reduciendo el tiempo de obtención de resultados y los costos. Además, la varia- 
ción de secuencias dentro de los productos amplificados puede permitir la identificación precisa de los hongos a nivel de especie [1 18, 124]. Esta prueba ha sido utilizada para la detección de varios hongos en muestras de sangre y suero $[1 \mid 8,125]$. Recientemente se ha desarrollado un nuevo método automatizado para la identificación de hongos patógenos a partir de diferentes muestras biológicas basado en la tecnología Lumine ${ }^{\circledR} \times M A P^{\circledR}$ (Luminex Corporation, Texas, Estados Unidos), utilizando perlas de microesferas recubiertas en su superficie con diferentes sondas de hibridación específicas de hongos que van a capturar el ADN con la secuencia complementaria de interés y va a ser detectado mediante fluorescencia. Esta tecnología permite el análisis de más de 100 secuencias dianas diferentes en cada pozo de reacción, a partir de una sola muestra y en un solo ensayo [126].

Aunque el diagnóstico basado en la PCR supera las limitaciones de otros métodos diagnósticos, aún presenta algunos inconvenientes que evitan que sea implementada en los laboratorios de diagnóstico micológico de rutina. La principal desventaja señalada es la falta de estandarización de las metodologías, lo que explica la variación de los resultados entre los laboratorios, afectando la reproducibilidad de los mismos. Además, se carece de pruebas comerciales estándar para su uso [72, I27].

\section{Secuenciación de ácidos nucleicos fúngicos}

El creciente progreso en la tecnología y la disponibilidad de las secuencias del genoma completo de muchos hongos ha facilitado que métodos basados en las secuencias del ADN tengan aplicación tanto en investigación como en el campo de la microbiología clínica para la identificación de diferentes microorganismos. La identificación se logra comparando la secuencia del producto de amplificación obtenida a partir de la muestra o cultivo con una base de datos de secuencias de especies conocidas. La secuenciación es un método rápido (puede lograrse con 24 horas de crecimiento del hongo), económico y específico, por lo que se considera candidato para convertirse en el estándar de referencia para la identificación de hongos [128, |29].

En la figura 5 se presenta el cromatograma de la secuencia de un fragmento de ITS fúngico. Los picos del cromatograma son el resultado de la detección y el registro de la fluorescencia indicativo de la presencia de cada nucleótido.

\section{Detección de proteínas fúngicas por MALDI-TOF}

En la última década la espectrometría de masas MALDI-TOF ha sido introducida en el campo de la microbiología para la identificación de diferentes microorganismos. Esta técnica permite la obtención de una huella peptídica, resultado de la ionización suave de las proteínas ribosomales. Los iones se separan en función de su relación masa-carga tras ser acelerados en un campo eléctrico, dando como resultado un espectro que se puede comparar con una base de datos de espectros de referencia para lograr la identificación [130] (véase figura 6). La identificación puede hacerse directamente a partir de las muestras clínicas o de los aislamientos fúngicos in vitro. La técnica es calificada por diferentes investigadores como una técnica de fácil implementación, confiable, rápida, precisa y costo-efectiva para la identificación de levaduras y hongos filamentosos de importancia médica [131-135].

La comparación de la identificación de diferentes hongos filamentosos por cultivo y por MAL-

DI-TOF ha demostrado que mientras el método convencional puede identificar correctamente 


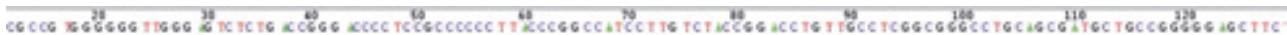

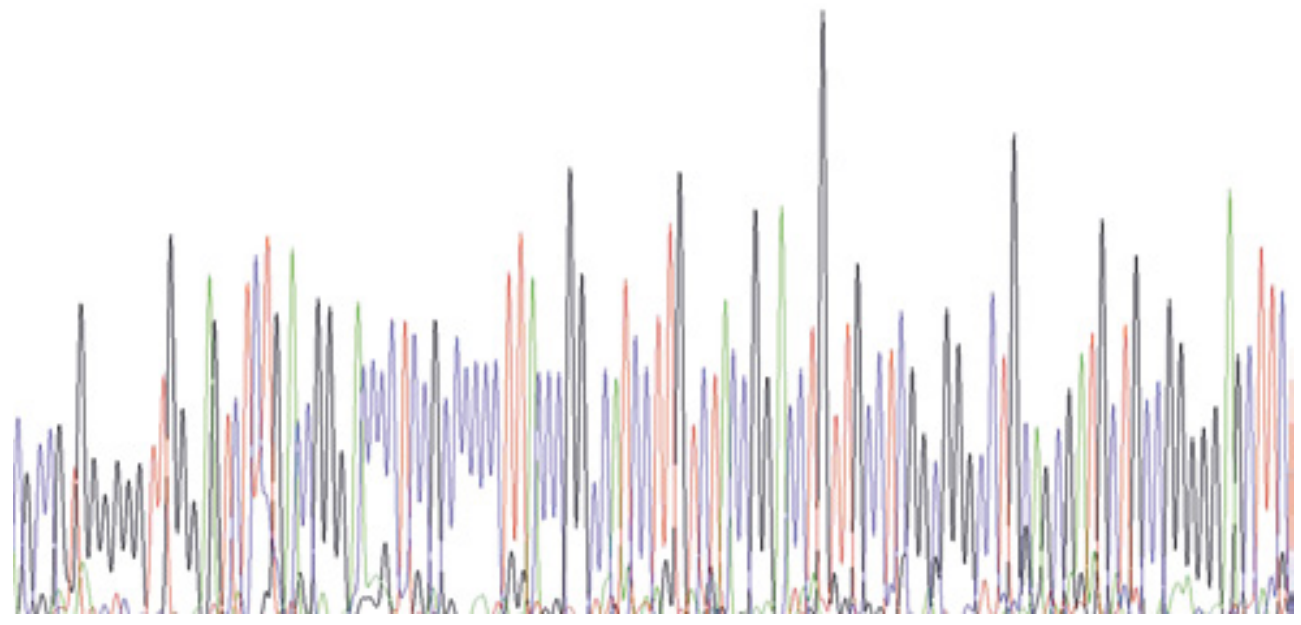

Figura 5. Cromatograma de la secuencia de un fragmento de ITS de Histoplasma capsulatum. Cada pico y color corresponde a un nucleótido: timina (rojo), adenina (verde), citosina (azul), guanina (negro). En la parte superior se especifica la secuencia que posteriormente se compara con las depositadas en un banco de datos de secuencias (GenBank) para la identificación del microorganismo de interés. Cortesía de la Dra. María José Buitrago, Instituto de Salud Carlos III. España.

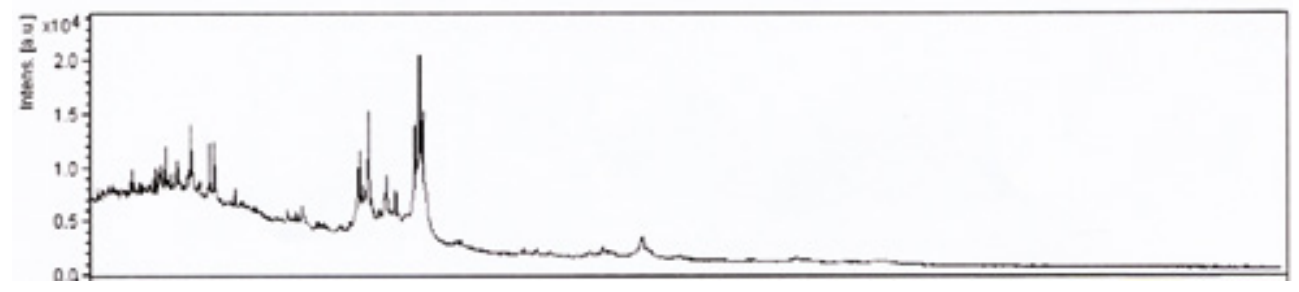

Figura 6. Espectro de proteínas de la forma micelial de Histoplasma capsulatum obtenido por MALDI-TOF. Cortesía de la Dra. María José Buitrago, Instituto de Salud Carlos III. España.

el 61,5\% de los aislamientos con el MALDI-TOF se pueden identificar hasta el 89\% [136]. Por otro lado, se ha demostrado que existe una diferencia importante en el tiempo que toma identificar levaduras utilizando los métodos tradicionales (aproximadamente 48 h) en comparación con la espectrometría de masas MALDI-TOF (menos de I h). Además, se ha calculado que el costo de la identificación por espectrometría de masas MALDI-TOF está por debajo de I,35€ (aproximadamente \$5.000 COP) [137].

\section{Consideraciones finales}

Finalmente, con la tabla 5 y la figura 7 pretendemos resaltar la información más relevante presentada en esta revisión. En la tabla 5 se presentan los principales métodos disponibles actualmente para el diagnóstico por el laboratorio de las infecciones fúngicas, incluyendo los métodos convencionales y las nuevas alternativas. Asimismo, en la figura 7 se presenta de manera general, la conducta a seguir en el laboratorio para el diagnóstico de una infección micótica a partir de diferentes muestras clínicas y los principales métodos empleados en cada caso. 


\section{Tabla 5. Principales métodos para diagnóstico micológico a partir de muestras biológicas}

\begin{tabular}{lll} 
Método & Ejemplo & Principal uso \\
\hline $\begin{array}{l}\text { Evaluación microscópica directa } \\
\text { Frescos }\end{array} \quad$ Solución salina & $\begin{array}{l}\text { Observación de blastoconidias, hifas o pseudohifas en flujo } \\
\text { vaginal }\end{array}$ \\
& Hidróxido de potasio $(\mathrm{KOH})$ al & $\begin{array}{l}\text { Observación de blastoconidias, pseudohifas, hifas septadas, } \\
\text { aseptadas, hialinas o dematiáceas, blastoconidias multigemantes } \\
\text { de Paracoccidioides spp., células escleróticas de Medlar }\end{array}$ \\
Tinciones & Gram & $\begin{array}{l}\text { Observación de blastoconidias, hifas o pseudohifas de Candida } \\
\text { spp., principalmente en orina, flujo vaginal y mucosa oral } \\
\text { Observación de blastoconidias, hifas o pseudohifas, princi- } \\
\text { palmente en sangre periférica y médula ósea. Ampliamente } \\
\text { utilizada para observar levaduras intracelulares de Histoplasma } \\
\text { capsulatum }\end{array}$
\end{tabular}

\section{Tinta China}

Blanco de calcoflúor

Hematoxilina-Eosina

Ácido peryódico de Schiff (PAS)/

Plata metenamina de Gomori-

Grocott

Fontana-Masson

Mucicarmín de Mayer

\section{Cultivo}

Medios de aislamiento

Agar Sabouraud dextrosa

Agar Micosel

Infusión de cerebro y corazón $(\mathrm{BHI})$

Medio bifásico con $\mathrm{BHI}$ (hemocultivos)

Agar cromogénico

Agar arroz/Agar Papa Dextrosa (PDA)

Medios Agar Dixon especializados

Agar con L-Dopa o Agar semilla de girasol

Agar urea
Detección levaduras capsuladas de Cryptococcus neoformans, principalmente en líquido cefalorraquídeo

Detección de blastoconidias, hifas o pseudohifas por microscopia de fluorescencia

Observación de hifas, pseudohifas, blastoconidias y cuerpos asteroides en tejido así como la respuesta inflamatoria del hospedero

Diferenciación de hifas, pseudohifas y blastoconidias en tejido

Detección de melanina o pigmentos similares principalmente en hongos dematiáceos y Cryptococcus spp.

Detección de mucopolisacáridos capsulares p. ej. en Cryptococcus neoformans

Aislamiento primario de hongos ambientales y patógenos a partir de muestras clínicas

Aislamiento primario de hongos patógenos, principalmente dermatofitos, a partir de muestras clínicas. Inhibe el crecimiento de bacterias y hongos ambientales contaminantes

Medio rico utilizado principalmente para la recuperación primaria de hongos ambientales y patógenos de difícil crecimiento. Además, para confirmar dimorfismo en hongos del complejo Sporothrix schenckii o Histoplasma capsulatum

Recuperación primaria de hongos en sangre, principalmente levaduras

Identificación presuntiva de levaduras principalmente del género Candida

Inducción de esporulación y producción de pigmentos para identificación fenotípica de hongos

Medio que contiene ácidos grasos que favorecen el crecimiento y aislamiento de hongos lipofílicos como Malassezia spp.

Aislamiento de Cryptococcus neoformans, evidenciado por la producción de un pigmento marrón en el agar, producto del metabolismo de ácido cafeico

Identificación de hongos que producen ureasa como Cryptococcus spp., Trichosporon spp., Rhodotorula spp. y Trichophyton interdigitale. La ureasa genera un cambio en el $\mathrm{pH}$, que es evidenciado por el cambio de color del medio a rosado-fucsia 


\section{Pruebas inmunológicas}

Detección Inmunodifusión de anticuerpos

Fijación del complemento

Inmunoensayo enzimático (ELISA)

Detección de antígenos

Aglutinación con partículas de látex

ELISA para I,3- $\beta$-D-glucano

ELISA para Mananos

ELISA para Galactomananos

Lateral Flow para antígenos secretados o capsulares

Cromatografía de gases acoplada a masas para la detección de compuestos volátiles

\section{Pruebas moleculares}

Ampli-

ficación

de ácidos

nucleicos

Secuencia-

ción

Técnicas basas en la reacción en cadena de la polimerasa (PCR)

Secuenciación de Sanger o pirosecuenciación

Identificación MALDI-TOF

de perfiles

proteicos
Detección de anticuerpos principalmente contra Aspergillus fumigatus, Histoplasma capsulatum, Paracoccidioides brasiliensis y Sporothrix schenkii

Detección de anticuerpos contra Histoplasma capsulatum y Paracoccidioides brasiliensis

Detección de anticuerpos contra Candida spp. y Aspergillus spp.

Detección del antígeno capsular de Crypotococcus neoformans

Detección del polisacárido de diferentes hongos (panfúngica) Detección del polisacárido de la pared de especies de Candida

Detección del polisacárido principalmente de la pared de Aspergillus spp.

Detección de antígenos de Aspergillus fumigatus y Cryptococcus neoformans por inmunocromatografía (Lateral Flow)

Detección de compuestos volátiles. De utilidad en el diagnóstico de infecciones pulmonares por Aspergillus spp.

Identificación de diferentes hongos tanto de muestras biológicas como de cultivos por la amplificación de diferentes dianas de ADN fúngico

Permiten la identificación de hongos a partir de muestras clínicas o de cultivos por secuenciación de dianas especificas

Identificación de diferentes hongos por la huella peptídica a partir de muestras clínicas y de cultivos

Tomado y modificado de Laboratory diagnostics of invasive fungal infections: an overview with emphasis on molecular approach por L. Bašková \& V. Buchta, 2012, Folia Microbiologica, 57, p. 423. Copyright 2012 por Institute of Microbiology, Academy of Sciences of the Czech Republic [72]

\section{Conclusiones}

A pesar de la amenaza que representan las infecciones fúngicas para la salud humana, en particular las invasivas y las diseminadas, debido a las altas tasas de morbilidad y mortalidad que causan, aún no se tiene la suficiente conciencia sobre la magnitud del problema, por lo que continúan siendo un desafío en lo que al control, el diagnóstico y el tratamiento se refiere.

Hasta ahora se han logrado importantes avances en el desarrollado de técnicas de laboratorio que apoyan el diagnostico micológico. Aunque algunas han contribuido a mejorar el diagnóstico, existen limitaciones para su implementación en los laboratorios dedicado al diagnóstico microbiológico de rutina por la falta de estandarización, la baja sensibilidad o especificidad, y por el costo de algunas de ellas. Por lo tanto, la búsqueda de una prueba sencilla, que supere en tiempo, sensibilidad y especificidad al examen directo y al cultivo, considerado actualmente el estándar de referencia, continúa siendo una tarea pendiente. 


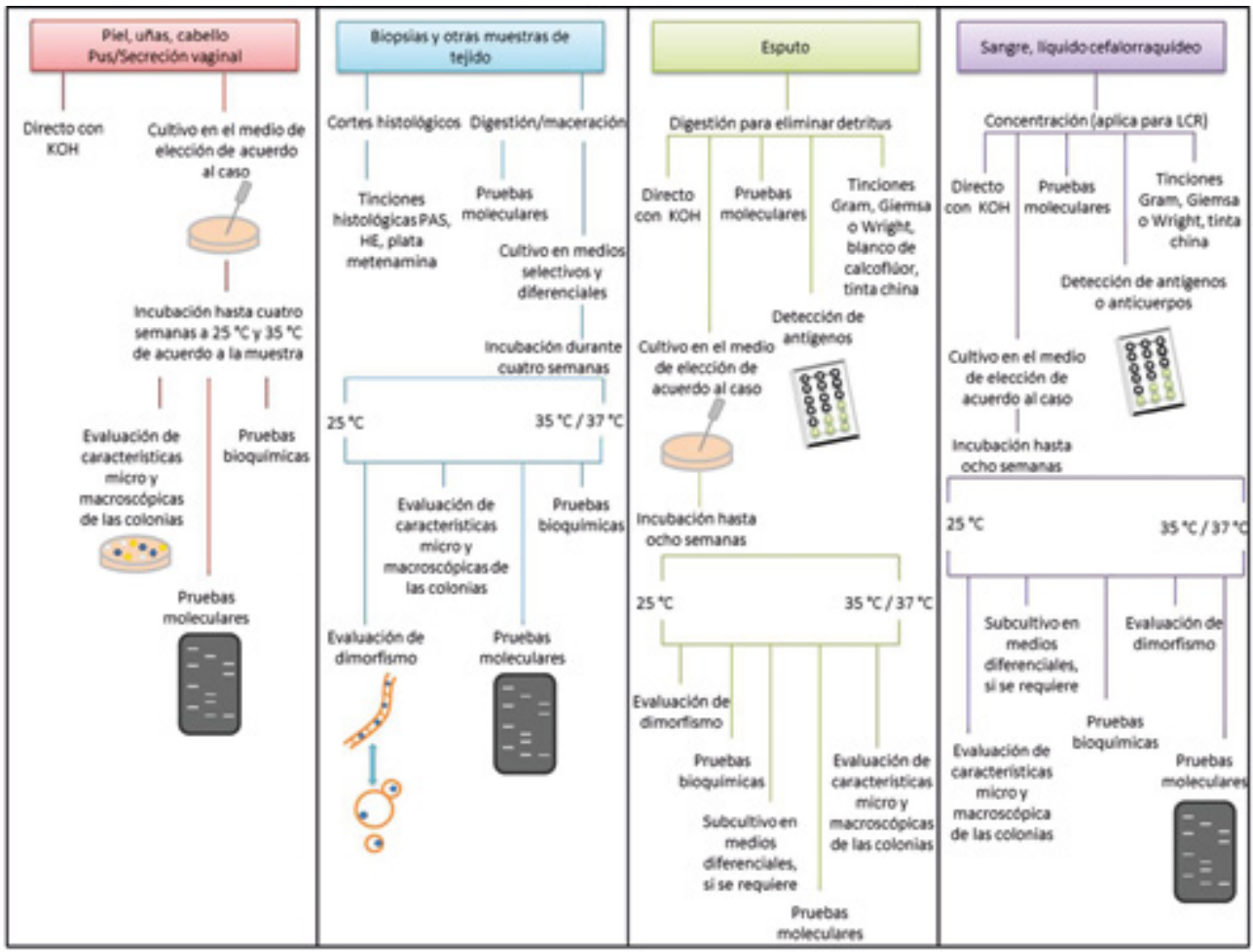

Figura 7. Algoritmo general a seguir en el procesamiento de las principales muestras biológicas en el laboratorio para el diagnóstico micológico. Tomado y modificado de The Fungi of Medical Importance (p. 67I) en: Foundations in Microbiology por K.P. Talaro \& B. Chess, 20I5, Nueva York, Estados Unidos: McGraw-Hill Education. Copyright ${ }^{\circledR} 2015$ por McGraw-Hill Education [I I].

\section{Agradecimientos}

A la Vicerrectoría de Investigación de la Universidad de Antioquia por el apoyo económico a la coautora Sindy V. Flórez-Muñoz en el marco del Programa Jóvenes Investigadores 2015.

\section{Bibliografía}

I. Binder U, Lzass-Florl C. Epidemiology of invasive fungal infections in the mediterranean area. Mediterr J Hematol Infect Dis 201 I; 3: e201 10016

2. Pfaller MA, Diekema DJ. Epidemiology of invasive mycoses in North America. Crit Rev Microbiol 20 I0; 36: I-53.

3. Pierce CG, Lopez-Ribot JL. Candidiasis drug discovery and development: new approaches targeting virulence for discovering and identifying new drugs. Expert Opin Drug Discov 2013; 8: 1117-1126.

4. Peman J, Salavert M. [General epidemiology of invasive fungal disease]. Enferm Infecc Microbiol Clin 2012; 30: 90-98.

5. Perfect JR. Fungal diagnosis: how do we do it and can we do better? Curr Med Res Opin 20 13; 29 Suppl 4: 3-1 1.
6. Pfaller MA, Diekema DJ. Epidemiology of invasive candidiasis: a persistent public health problem. Clin Microbiol Rev 2007: 20: 133-163.

7. Mora C, Tittensor DP, Adl S, Simpson AG, Worm B. How many species are there on Earth and in the ocean? PLoS Biol 20 I I; 9: el00। I 27.

8. Schmit JP, Mueller GM. An estimate of the lower limit of global fungal diversity. Biodivers Conserv 2006; 16: 99 III.

9. Garcia-Solache MA, Casadevall A. Global warming will bring new fungal diseases for mammals. MBio 20 I0; I.

10. Jain N, Fries BC. Fungal Infections in Humans. eLS. Chichester, Inglaterra: John Wiley \& Sons, Ltd; 20II. 
II. Talaro KP, Chess B. The Fungi of Medical Importance. Foundations in Microbiology (ed 9a). Nueva York, Estados Unidos: McGraw-Hill Education; 2015.

12. Brown GD, Denning DW, Gow NA, Levitz SM, Netea MG, White TC. Hidden killers: human fungal infections. Sci Transl Med 20 I2; 4: I65rv I 13.

13. Richardson M, Lass-Florl C. Changing epidemiology of systemic fungal infections. Clin Microbiol Infect 2008; I4 Suppl 4: 5-24.

14. Hsu LY, Wijaya L, Shu-Ting Ng E, Gotuzzo E. Tropical fungal infections. Infect Dis Clin North Am 20 2; 26: 497512.

15. Ribeiro CS, Zaitz C, Framil VM, Ottoboni TS, Tonoli MS, Ribeiro RP. Descriptive study of onychomycosis in a hospital in Sao Paulo. Braz J Microbiol 20I5; 46: 485-492.

16. Cruz Ch R, Ponce E E, Calderón R L, Delgado V N, VieiIle O P, Piontelli L E. Micosis superficiales en la ciudad de Valparaíso, Chile: Período 2007-2009. Rev Chil Infect 20I I; 28: 40-409.

17. Martinez Mendez D, Hernandez Valles R, Alvarado P, Mendoza M. [Mycoses in Venezuela: Working Groups in Mycology reported cases (1984-20 I0)]. Rev lberoam Micol 20 I3; 30: 39-46.

18. Sugui JA, Kwon-Chung KJ, Juvvadi PR, Latge JP, Steinbach WJ. Aspergillus fumigatus and related species. Cold Spring Harb Perspect Med 2015; 5: a019786.

19. Nucci M, Anaissie E. Fusarium infections in immunocompromised patients. Clin Microbiol Rev 2007; 20: 695-704.

20. Nucci M, Queiroz-Telles F, Tobon AM, Restrepo A, Colombo AL. Epidemiology of opportunistic fungal infections in Latin America. Clin Infect Dis 20 10; 51: 561-570.

21. Meyer W, Castaneda A, Jackson S, Huynh M, Castaneda E. Molecular typing of IberoAmerican Cryptococcus neoformans isolates. Emerg Infect Dis 2003; 9: I89-195.

22. Sanclemente G, Mahecha M, Guzman C. Enfermedades de la piel más frecuentes en la consulta externa dermatológica del Hospital Universitario San Vicente de Paúl y del Hospital Infantil. Medellín, 1999 Acta Méd Colomb 200 I; 26: 240-244.

23. Mejía-Arango MA, Santa-Vélez C, Cadavid-Sierra M, Vélez LM, Colmenares LM, Restrepo-Jaramillo BN, et al. Estudio etiológico y epidemiológico de las micosis cutáneas en un laboratorio de referencia - Antioquia - Colombia. CES Med 20। 3; 27: 7-19.

24. Zuluaga de C A, de Bedout C, Tabares A, Cano LE, Restrepo A, Arango M, et al. Comportamiento de los agentes etiológicos de las onicomicosis en un laboratorio de micologia de referencia (Medellín 1994-2003). Med Cutan Iber Lat Am 2005; 33: 25I-256.

25. Rubio G, Sanchez G, Porras L, Alvarado Z. [Sporotrichosis: prevalence, clinical and epidemiological features in a reference center in Colombia]. Rev Iberoam Micol 20 10; 27: 75-79.

26. Mesa Arango A, Sánchez M. Esporotricosis: una experiencia en Medellín, Antioquia. Rev Mex Micol 2000; 16: II-I6.

27. Calle D, Rosero DS, Orozco LC, Camargo D, Castaneda E, Restrepo A. Paracoccidioidomycosis in Colombia: an ecological study. Epidemiol Infect 200 I; 126: 309-3I5.

28. Restrepo A, Benard G, de Castro CC, Agudelo CA, Tobon AM. Pulmonary paracoccidioidomycosis. Semin Respir Crit Care Med 2008; 29: 182-197.

29. Torrado E, Castañeda E, de la Hoz F, Restrepo A. Paracoccidioidomicocis: definición de las áreas endémicas de Colombia. Biomédica 2000; 20: 327-334.

30. The Society for Leukocyte Biology. Membership directory. The Society for Leukocyte Biology. J Leukoc Biol 1989; 46: 367-405.

3I. Escandón P, de Bedout C, Lizarazo J, Agudelo Cl, Tobón Á, Bello S, et al. Cryptococcosis in Colombia: Results of the national surveillance program for the years 20062010. Biomédica 2012; 32: 386-398.

32. Cortes JA, Jaimes JA, Leal AL. [Incidence and prevalence of candidemia in critically ill patients in Colombia]. Rev Chilena Infectol 20I3; 30: 599-604.

33. Ortiz Ruiz G, Osorio J, Valderrama S, Alvarez D, Elias Diaz R, Calderon J, et al. Risk factors for candidemia in non-neutropenic critical patients in Colombia. Med Intensiva 2015.

34. Tille PM. Ovenview of Fungal Identification Methods and Strategies. En: Tille PM, ed. Bailey \& Scott's Diagnostic Microbiology (ed 13a). Misuri, Estados Unidos: Elsevier Mosby; 20I4: 705-73I.

35. Mendoza N, Palacios CP, Cardona N, Gómez Vargas LM. Onicomicosis: afección común de difícil tratamiento. Rev Asoc Colomb Dermatol 20 I2; 20: I49-I58.

36. Feuilhade de Chauvin M. [Treatment of onychomycosis]. J Mycol Med 20I4; 24: 296-302

37. Mahajan VK. Sporotrichosis: an overview and therapeutic options. Dermatol Res Pract 2014; 2014: 272376.

38. Krzysciak PM, Pindycka-Piaszczynska M, Piaszczynski M. Chromoblastomycosis. Postepy Dermatol Alergol 2014; 31: 310-321.

39. Welsh O, Al-Abdely HM, Salinas-Carmona MC, Fahal $\mathrm{AH}$. Mycetoma medical therapy. PLoS Negl Trop Dis 2014; 8: e3218.

40. Francesconi VA, Klein AP, Santos AP, Ramasawmy R, Francesconi F. Lobomycosis: epidemiology, clinical presentation, and management options. Ther Clin Risk Manag 20।4; 10: 85।-860.

4I. Leroy O, Gangneux JP, Montravers P, Mira JP, Gouin F, Sollet JP, et al. Epidemiology, management, and risk factors for death of invasive Candida infections in critical care: a multicenter, prospective, observational study in France (2005-2006). Crit Care Med 2009; 37: 1612-1618.

42. Patel PK, Erlandsen JE, Kirkpatrick WR, Berg DK, Westbrook SD, Louden C, et al. The Changing Epidemiology of Oropharyngeal Candidiasis in Patients with HIVI AIDS in the Era of Antiretroviral Therapy. AIDS Res Treat 2012; 2012: 26247|.

43. Sobel JD. Vulvovaginal candidosis. Lancet 2007; 369: |96|-197|.

44. Horn DL, Neofytos D, Anaissie EJ, Fishman JA, Steinbach WJ, Olyaei A], et al. Epidemiology and outcomes of candidemia in 2019 patients: data from the pro- 
spective antifungal therapy alliance registry. Clin Infect Dis 2009; 48: 1695-1703.

45. Del Palacio A, Villar J, Alhambra A. [Epidemiology of invasive candidiasis in pediatric and adult populations]. Rev Iberoam Micol 2009; 26: 2-7.

46. Spellberg B, Marr K, SG F. En: Calderone RA CC, ed Candida and Candidiasis. Washington, DC: ASM Press; 2012: 225-242.

47. Almirante B, Rodriguez D, Park BJ, Cuenca-Estrella M, Planes AM, Almela M, et al. Epidemiology and predictors of mortality in cases of Candida bloodstream infection: results from population-based surveillance, barcelona, Spain, from 2002 to 2003. J Clin Microbiol 2005; 43: I829- 835.

48. Chai LY, Denning DW, Warn P. Candida tropicalis in human disease. Crit Rev Microbiol 20 I0; 36: 282-298.

49. Ngamskulrungroj P, Chang Y, Roh J, Kwon-Chung KJ. Differences in nitrogen metabolism between Cryptococcus neoformans and C. gattii, the two etiologic agents of cryptococcosis. PLoS One 20 I2; 7: e34258.

50. Byrnes EJ, 3rd, Bartlett KH, Perfect JR, Heitman J. Cryptococcus gattii: an emerging fungal pathogen infecting humans and animals. Microbes Infect 20I I; I3: 895-907.

5I. Colombo AL, Padovan AC, Chaves GM. Current knowledge of Trichosporon spp. and Trichosporonosis. Clin Microbiol Rev 201 I; 24: 682-700.

52. Montagna MT, Caggiano G, Lovero G, De Giglio O, Coretti C, Cuna T, et al. Epidemiology of invasive fungal infections in the intensive care unit: results of a multicenter Italian survey (AURORA Project). Infection 20 I3; 41: 645653.

53. Alastruey-Izquierdo A, Mellado E, Pelaez T, Peman J, Zapico S, Alvarez M, et al. Population-based survey of filamentous fungi and antifungal resistance in Spain (FILPOP Study). Antimicrob Agents Chemother 2013; 57: 33803387.

54. Morace G, Borghi E. Invasive mold infections: virulence and pathogenesis of mucorales. Int J Microbiol 20 I2; 20I2: 349278.

55. Latge JP. Aspergillus fumigatus and aspergillosis. Clin Microbiol Rev 1999; 12: 310-350.

56. Lass-Florl C, Griff K, Mayr A, Petzer A, Gastl G, Bonatti $\mathrm{H}$, et al. Epidemiology and outcome of infections due to Aspergillus terreus: 10-year single centre experience. $\mathrm{Br}$ | Haematol 2005; 131: 201-207.

57. Kontoyiannis DP, Lewis RE, May GS, Osherov N, Rinaldi MG. Aspergillus nidulans is frequently resistant to amphotericin B. Mycoses 2002; 45: 406-407.

58. Krishnan S, Manavathu EK, Chandrasekar PH. Aspergillus flavus: an emerging non-fumigatus Aspergillus species of significance. Mycoses 2009; 52: 206-222.

59. Balajee SA, Gribskov JL, Hanley E, Nickle D, Marr KA. Aspergillus lentulus sp. nov., a new sibling species of A. fumigatus. Eukaryot Cell 2005; 4: 625-632.

60. Nucci M, Varon AG, Garnica M, Akiti T, Barreiros G, Trope BM, et al. Increased incidence of invasive fusariosis with cutaneous portal of entry, Brazil. Emerg Infect Dis 2013; 19: 1567-1572.
61. Muhammed M, Coleman J, Carneiro HA, Mylonakis E. The challenge of managing fusariosis. Virulence 201 I; 2: 91-96.

62. Esnakula AK, Summers I, Naab TJ. Fatal disseminated fusarium infection in a human immunodeficiency virus positive patient. Case Rep Infect Dis 20 I3; 2013 : 379320.

63. Kontoyiannis DP, Lewis RE. How I treat mucormycosis. Blood 2011; I 18: 1216-1224.

64. Hage CA, Knox KS, Wheat LJ. Endemic mycoses: overlooked causes of community acquired pneumonia. Respir Med 20।2; 106: 769-776.

65. Marques SA. Paracoccidioidomycosis. Clin Dermatol 2012; 30: 610-615

66. Chakrabarti A, Bonifaz A, Gutierrez-Galhardo MC, Mochizuki T, Li S. Global epidemiology of sporotrichosis. Med Mycol 2015; 53: 3-14.

67. Jarboui MA, Mseddi F, Sellami H, Sellami A, Makni F, Ayadi A. [Pneumocystis: epidemiology and molecular approaches]. Pathol Biol (Paris) 2013; 61: 239-244.

68. Kauffman CA. Pearls in Establishing a Clinical Diagnosis: Signs and Symptoms. En: Maertens JA, Marr KA, eds. Diagnosis of Fungal Infections. Nueva York, Estados Unidos: Informa Healthcare USA, Inc;; 2007: I- 17.

69. Abu-Elteen $\mathrm{KH}$, Hamad MA. Changing Epidemiology of Classical and Emerging Human Fungal Infections: A Review. Jordan J Biol Sci 20 2; 5: 215-230.

70. Rezaei-Matehkolaei A, Mirhendi H, Makimura K, de Hoog GS, Satoh K, Najafzadeh MJ, et al. Nucleotide sequence analysis of beta tubulin gene in a wide range of dermatophytes. Med Mycol 20 I4; 52: 674-688.

7I. Monod M, Lurati M, Baudraz-Rosselet F. [Diagnosis of non dermatophyte onychomycosis ant its relevance for treatment]. Rev Med Suisse 20 I3; 9: 730-733.

72. Baskova L, Buchta V. Laboratory diagnostics of invasive fungal infections: an overview with emphasis on molecular approach. Folia Microbiol (Praha) 2012; 57: 421-430.

73. Bernal-Martinez L, Alastruey-lzquierdo A, CuencaEstrella M. Diagnostics and susceptibility testing in Aspergillus. Future Microbiol 20 16; I I: 315-328.

74. Ayats J, Martin-Mazuelos E, Peman J, Quindos G, Sanchez F, Garcia-Rodriguez J, et al. [Spanish Society of Clinical Microbiology and Infectious Diseases (SEIMC) guidelines for the diagnosis of invasive fungal infections. 2010 update]. Enferm Infecc Microbiol Clin 20 I ; 29: 39 e3I- 15.

75. Chaya AK, Pande S. Methods of specimen collection for diagnosis of superficial and subcutaneous fungal infections. Indian J Dermatol Venereol Leprol 2007; 73: 202-205.

76. Mulla AF, Shah AA, Koshy AV, Mayank M. Laboratory diagnosis of fungal infection. Univ Res J Dent 20I5; 5: 49-53.

77. Verweij PE, van der Lee HAL, Rijs AJMM. The Role of Conventional Diagnostic Tools. En: Maertens JA, Marr KA, eds. Diagnosis of Fungal Infections. Nueva York, Estados Unidos: Informa Healthcare USA, Inc:; 2007: 19-39.

78. Guarner J, Brandt ME. Histopathologic diagnosis of fungal infections in the 2 I st century. Clin Microbiol Rev 20I I; 24: 247-280.

79. Quindos G, Eraso E, Lopez-Soria LM, Ezpeleta G. [lnvasive fungal disease: conventional or molecular mycological diagnosis?]. Enferm Infecc Microbiol Clin 20 2; 30: 560-57I. 
80. Kozel TR, Wickes B. Fungal diagnostics. Cold Spring Harb Perspect Med 20 I4; 4: a0 19299.

81. Lamoth F, Alexander BD. Nonmolecular methods for the diagnosis of respiratory fungal infections. Clin Lab Med 2014; 34: 315-336.

82. Guimaraes AJ, Pizzini CV, De Matos Guedes HL, Albuquerque PC, Peralta JM, Hamilton AJ, et al. ELISA for early diagnosis of histoplasmosis. J Med Microbiol 2004; 53: 509-5। 4

83. de Azevedo PZ, Sylvestre TF, Cavalcante Rde S, de Carvalho LR, Moris DV, de Oliveira ML, et al. Evaluation of the Double Agar Gel Immunodiffusion Test and of the Enzyme-Linked Immunosorbent Assay in the Diagnosis and Follow-Up of Patients with Chronic Pulmonary Aspergillosis. PLoS One 20 15; I0: e0 I 3484I.

84. Alvarado $P$, Ostos $A$, Franquiz N, Roschman-Gonzalez A, Zambrano EA, Mendoza M. [Serological diagnosis of sporotrichosis using an antigen of Sporothrix schenckii sensu stricto mycelium]. Invest Clin 20 I5; 56: I | I- I 22.

85. Held J, Kohlberger I, Rappold E, Busse Grawitz A, Hacker G. Comparison of ( I->3)-beta-D-glucan, mannan/anti-mannan antibodies, and Cand-Tec Candida antigen as serum biomarkers for candidemia. J Clin Microbiol 2013; 5।: |158-1164.

86. Mikulska M, Calandra T, Sanguinetti M, Poulain D, Viscoli $C$. The use of mannan antigen and anti-mannan antibodies in the diagnosis of invasive candidiasis: recommendations from the Third European Conference on Infections in Leukemia. Crit Care 20 I0; 14: R222.

87. Fernandes VC, Coitinho JB, Veloso JM, Araujo SA, Pedroso EP, Goes AM. Combined use of Paracoccidioides brasiliensis recombinant $\mathrm{rPb} 27$ and $\mathrm{rPb} 40$ antigens in an enzyme-linked immunosorbent assay for immunodiagnosis of paracoccidioidomycosis. J Immunol Methods 201 I; 367: 78-84.

88. Zhang X, Gibson B, Jr., Daly TM. Evaluation of commercially available reagents for diagnosis of histoplasmosis infection in immunocompromised patients. J Clin Microbiol 2013; 51: 4095-4I01.

89. Hage CA, Ribes JA, Wengenack NL, Baddour LM, Assi M, McKinsey DS, et al. A multicenter evaluation of tests for diagnosis of histoplasmosis. Clin Infect Dis 201 I; 53: 448-454.

90. De Pauw B, Walsh TJ, Donnelly JP, Stevens DA, Edwards JE, Calandra T, et al. Revised definitions of invasive fungal disease from the European Organization for Research and Treatment of Cancer/Invasive Fungal Infections Cooperative Group and the National Institute of Allergy and Infectious Diseases Mycoses Study Group (EORTC/MSG) Consensus Group. Clin Infect Dis 2008; 46: $|8| 3-182 \mid$

91. Einsele H, Loeffler J. Contribution of new diagnostic approaches to antifungal treatment plans in high-risk haematology patients. Clin Microbiol Infect 2008; I 4 Suppl 4: $37-45$.

92. Lu Y, Chen YQ, Guo YL, Qin SM, Wu C, Wang K. Diagnosis of invasive fungal disease using serum ( 1 -->3)-beta-D-glucan: a bivariate meta-analysis. Intern Med 201 I; 50: $2783-279$ |
93. Arvanitis M, Mylonakis E. Diagnosis of invasive aspergillosis: recent developments and ongoing challenges. Eur J Clin Invest 2015; 45: 646-652.

94. Kauffman CA, Bergman AG, Severance PJ, McClatchey KD. Detection of cryptococcal antigen. Comparison of two latex agglutination tests. Am J Clin Pathol I981; 75: 106- 109.

95. Wang $\mathrm{H}$, Yuan $\mathrm{X}$, Zhang $\mathrm{L}$. Latex agglutination: diagnose the early cryptococcus neoformans test of capsular polysaccharide antigen. Pak J Pharm Sci 20 15; 28: 307-3 II.

96. Thornton CR. Development of an immunochromatographic lateral-flow device for rapid serodiagnosis of invasive aspergillosis. Clin Vaccine Immunol 2008; I5: I095-I I 05.

97. Pan Z, Fu M, Zhang J, Zhou H, Fu Y, Zhou J. Diagnostic accuracy of a novel lateral-flow device in invasive aspergillosis: a meta-analysis. J Med Microbiol 20I5; 64: 702-707.

98. White PL, Parr C, Thornton C, Barnes RA. Evaluation of real-time PCR, galactomannan enzyme-linked immunosorbent assay (ELISA), and a novel lateral-flow device for diagnosis of invasive aspergillosis. J Clin Microbiol 20 I3; 5 I: I510-1516

99. de Heer K, van der Schee MP, Zwinderman K, van den Berk IA, Visser CE, van Oers R, et al. Electronic nose technology for detection of invasive pulmonary aspergillosis in prolonged chemotherapy-induced neutropenia: a proof-of-principle study. J Clin Microbiol 20 I3; 5I: 14901495.

100. Koo S, Thomas HR, Daniels SD, Lynch RC, Fortier SM, Shea MM, et al. A breath fungal secondary metabolite signature to diagnose invasive aspergillosis. Clin Infect Dis 2014; 59: 1733-1740.

10I. Heddergott C, Calvo AM, Latge JP. The volatome of Aspergillus fumigatus. Eukaryot Cell 20 14; 13: 10 I4- 025.

102. Hoog G, Guarro J, Tan C, Wintermans R, Gené J. Hyphomycetes. En: Hoog G, Guarro J, Gené J, Figueras M, eds. Atlas of clinical fungi (ed 2da). Utrecht, Países Bajos: ASM Press; 2000: 380- 1007.

103. Coleman JJ, Muhammed M, Kasperkovitz PV, Vyas JM, Mylonakis E. Fusarium pathogenesis investigated using Galleria mellonella as a heterologous host. Fungal Biol 2011; I15: 1279-1289.

104. Kurzai O. Human Fungal Pathogens (ed 2da). Berlín, Alemania: Springer-Verlag Berlin Heidelberg; 2014.

105. Bhabhra R, Askew DS. Thermotolerance and virulence of Aspergillus fumigatus: role of the fungal nucleolus. Med Mycol 2005; 43 Suppl I: S87-93.

106. Anaissie EJ, McGinnis MR, Pfaller MA. Clinical Mycology (ed 2da). Edimburgo, Escocia: Churchill Livingstone; 2009.

107. Szaniszlo PJ. Fungal Dimorphism with Emphasis on Fungi Pathogenic for Humans. Nueva York, Estados Unidos: Springer US; 1985.

108. Neppelenbroek KH, Seo RS, Urban VM, Silva S, Dovigo $\mathrm{LN}$, Jorge $\mathrm{JH}$, et al. Identification of Candida species in the clinical laboratory: a review of conventional, commercial, and molecular techniques. Oral Dis 20 I4; 20: 329-344.

109. Balajee SA, Lindsley MD, labal N, Ito J, Pappas PG, Brandt ME. Nonsporulating clinical isolate identified as Petromyces alliaceus (anamorph Aspergillus alliaceus) by morphological and sequence-based methods. J Clin Mi- 
crobiol 2007; 45: 2701-2703.

I 10. Paniz-Mondolfi A, Talhari C, Sander Hoffmann L, Connor DL, Talhari S, Bermudez-Villapol L, et al. Lobomycosis: an emerging disease in humans and delphinidae. Mycoses 2012; 55: 298-309.

I I I. Hazen KC. Respiratory fungal infections: molecular diagnostic tests. Clin Lab Med 20 14; 34: 35 I-364.

I 12. Rola B, Pawlik A, Frac M, Malek W, Targonski Z, Rogalski J, et al. The phenotypic and genomic diversity of Aspergillus strains producing glucose dehydrogenase. Acta Biochim Pol 2015; 62: 747-755.

I13. Gabal MA. Development of a chromosomal DNA probe for the laboratory diagnosis of aspergillosis. Mycopathologia 1989; 106: 121-129.

I14. Moncada PA, Budvytiene I, Ho DY, Deresinski SC, Montoya JG, Banaei N. Utility of DNA sequencing for direct identification of invasive fungi from fresh and formalin-fixed specimens. Am J Clin Pathol 2013; I40: 203-208.

I 15. Ranque S, Normand AC, Cassagne C, Murat JB, Bourgeois $\mathrm{N}$, Dalle $\mathrm{F}$, et al. MALDI-TOF mass spectrometry identification of filamentous fungi in the clinical laboratory. Mycoses 2014; 57: 135-140.

I 16. Rodrigues AM, de Hoog GS, de Camargo ZP. Molecular Diagnosis of Pathogenic Sporothrix Species. PLoS Negl Trop Dis 2015; 9: e0004190.

I 17. White TJ, Bruns T, Lee S, Taylor J. Amplification and direct sequencing of fungal ribosomal RNA genes for phylogenetics. En: Innis MA, Gelfand DH, Sninsky J), White TJ, eds. PCR Protocols: A Guide to Methods and Applications. Califomia, Estados Unidos: Academic Press Inc. 1990: 315-322.

I 18. Khot PD, Fredricks DN. PCR-based diagnosis of human fungal infections. Expert Rev Anti Infect Ther 2009; 7 $1201-1221$.

I 19. Sanguinetti M, Posteraro B, Pagano L, Pagliari G, Fianchi $\mathrm{L}$, Mele L, et al. Comparison of real-time PCR, conventional PCR, and galactomannan antigen detection by enzyme-linked immunosorbent assay using bronchoalveolar lavage fluid samples from hematology patients for diagnosis of invasive pulmonary aspergillosis. J Clin Microbiol 2003; 41 : 3922-3925.

120. Sun W, Wang K, Gao W, Su X, Qian Q, Lu X, et al. Evaluation of PCR on bronchoalveolar lavage fluid for diagnosis of invasive aspergillosis: a bivariate metaanalysis and systematic review. PLoS One 201 I; 6: e28467.

121. Johnson GL, Bibby DF, Wong S, Agrawal SG, Bustin SA. A MIQE-compliant real-time PCR assay for Aspergillus detection. PLoS One 2012; 7: e40022.

122. McMullan R, Metwally L, Coyle PV, Hedderwick S, McCloskey B, O'Neill HJ, et al. A prospective clinical trial of a real-time polymerase chain reaction assay for the diagnosis of candidemia in nonneutropenic, critically ill adults. Clin Infect Dis 2008; 46: 890-896.

123. Das S, Larone DH. Basics of molecular methods for fungal identification En: Larone DH, ed. Medically important fungi: a guide to identification (ed 5a). Washington D.C., Estados Unidos: ASM Press; 201 I: 317-335.

I24. Fortun J, Meije Y, Buitrago MJ, Gago S, Bernal-Martinez
L, Peman J, et al. Clinical validation of a multiplex real-time PCR assay for detection of invasive candidiasis in intensive care unit patients. J Antimicrob Chemother 2014; 69: 3|34-3|4|.

125. Lau A, Halliday C, Chen SC, Playford EG, Stanley K, Sorrell TC. Comparison of whole blood, serum, and plasma for early detection of candidemia by multiplex-tandem PCR. J Clin Microbiol 2010; 48: 8। I-8I6.

126. Landlinger C, Preuner S, Willinger B, Haberpursch B, Racil Z, Mayer J, et al. Species-specific identification of a wide range of clinically relevant fungal pathogens by use of Luminex XMAP technology. J Clin Microbiol 2009; 47: 1063 1073.

127. Arvanitis M, Anagnostou T, Fuchs BB, Caliendo AM, Mylonakis E. Molecular and nonmolecular diagnostic methods for invasive fungal infections. Clin Microbiol Rev 2014; $27: 490-526$

128. Balajee SA, Sigler L, Brandt ME. DNA and the classical way: identification of medically important molds in the 2 Ist century. Med Mycol 2007; 45: 475-490.

129. Romanelli AM, Sutton DA, Thompson EH, Rinaldi MG, Wickes BL. Sequence-based identification of filamentous basidiomycetous fungi from clinical specimens: a cautionary note. J Clin Microbiol 2010; 48: 741-752

130. CADTH Rapid Response Reports. MALDI-TOF Mass Spectrometry for Pathogen Identification: A Review of Accuracy and Clinical Effectiveness. Ottawa, Canadá: Canadian Agency for Drugs and Technologies in Health; 2015.

I31. Webster J, Oxley D. Protein Identification by MALDI-TOF Mass Spectrometry. En: Zanders DE, ed. Chemical Genomics and Proteomics: Reviews and Protocols. Nueva Jersey, Estados Unidos: Humana Press; 20 I2: 227-240.

132. Ferreira L, Sanchez-Juanes F, Gonzalez-Avila M, Cembrero-Fucinos D, Herrero-Hernandez A, GonzalezBuitrago JM, et al. Direct identification of urinary tract pathogens from urine samples by matrix-assisted laser desorption ionization-time of flight mass spectrometry. J Clin Microbiol 2010; 48: 21 10-21 I5

133. Clark AE, Kaleta EJ, Arora A, Wolk DM. Matrix-assisted laser desorption ionization-time of flight mass spectrometry: a fundamental shift in the routine practice of clinical microbiology. Clin Microbiol Rev 2013; 26: 547-603.

134. Chalupova J, Raus M, Sedlarova M, Sebela M. Identification of fungal microorganisms by MALDI-TOF mass spectrometry. Biotechnol Adv 2014; 32: 230-241.

135. Ferreira L, Sanchez-Juanes F, Vega M, Gonzalez M, Garcia MI, Rodriguez S, et al. Identification of fungal clinical isolates by matrix-assisted laser desorption ionizationtime-of-flight mass spectrometry. Rev Esp Quimioter 2013; 26: 193-197.

136. Becker PT, de Bel A, Martiny D, Ranque S, Piarroux $R$, Cassagne $C$, et al. Identification of filamentous fungi isolates by MALDI-TOF mass spectrometry: clinical evaluation of an extended reference spectra library. Med Mycol 2014; 52: 826-834

137. Sow D, Fall B, Ndiaye M, Ba BS, Sylla K, Tine R, et al. Usefulness of MALDI-TOF Mass Spectrometry for Routine Identification of Candida Species in a Resource-Poor Setting. Mycopathologia 2015; 180: 173-179. 